\title{
Evaluating Water Balance Variables under Land Use and Climate Projections in Heavily Forested Watershed in a Humid Region
}

\author{
Yashar Makhtoumi ${ }^{1}$, Simeng $\mathrm{Li}^{2}$, Victor Ibeanusi ${ }^{3}$, and Gang Chen ${ }^{1}$ \\ ${ }^{1}$ Florida State University \\ ${ }^{2}$ California State Polytechnic University Pomona \\ ${ }^{3}$ Florida A\&M University
}

June 22, 2020

\begin{abstract}
The hydrological processes in Upper Choctawhatchee River Watershed were modeled using the Soil and Water Assessment Tool (SWAT) to investigate the impacts of climate and land use change. We integrated land use projection based in the Shared Socioeconomic Pathways with future climate data to study the combined effects on Hydrological response of the watershed. Future rainfall and temperature, for two time periods, were obtained using General Climate Models to provide SWAT with the climatic forcing in order to project water balance variables. The simulation was carried out under two radiative forcing pathways of RCP4.5 and RCP6.0. Model calibration metrics of NSE, R2, and p-factor were $0.88,0.89$, and 0.68, respectively. Results revealed increases as high as 2.55 and 2.4 for average annual minimum and maximum temperature, respectively, especially during Summer and Winter. Average annual precipitation was estimated to increase up to $11 \%$ under both emission scenarios; however, under severe emissions of RCP6.0, it was projected for two decades earlier. Land use change focused on urbanization dominated the climate changes. Impacts on water balance variables differed seasonally. Results showed surface runoff experienced major changes under both emission scenarios in some months up to 5 times increase. Among the water balance variables, ET as the least dominant pathways for water loss, showed the modest changes with the largest decrease during Fall and Summer. Projection indicated more frequent extreme behavior regarding water balance during midcentury. Discharge was estimated to increase through the year and the highest changes were projected during Summer and Fall with $186.3 \%$ increase in November under RCP6.0. Relying on rainfall for farming along with reduced agricultural landuse (11.8\%) and increased urban area (47\%) and population growth, would likely make the water use efficiency critical. The model demonstrated satisfactory performance, capturing the hydrologic parameters. It thus can be used for further modelling of water quality to determine the sustainable conservation practices, extreme weather events such as hurricane and tropical storms.
\end{abstract}

\section{Evaluating Water Balance Variables under Land Use and Climate Projections in Heavily} Forested Watershed in a Humid Region

Yashar Makhtoumi ${ }^{1,}{ }^{*}$, Simeng Li $^{2}$, Victor Ibeanusi ${ }^{3}$ and Gang Chen ${ }^{1}$

${ }^{1}$ Department of Civil and Environmental Engineering, FAMU-FSU College of Engineering, Tallahassee, FL 32310

${ }^{2}$ Department of Civil Engineering, California State Polytechnic University Pomona, Pomona, CA 91709

${ }^{3}$ School of the Environment, Florida A\&M University, Tallahassee, FL 32306

${ }^{*}$ Corresponding author

Department of Civil and Environmental Engineering

FAMU-FSU College of Engineering 
Florida State University 2525 Pottsdamer Street, Tallahassee, FL 32310 Voice: (850) 4106303 Fax: (850) 4106142 Email: ymakhtoumi@fsu.edu

Abstract

The hydrological processes in Upper Choctawhatchee River Watershed were modeled using the Soil and Water Assessment Tool (SWAT) to investigate the impacts of climate and land use change. We integrated land use projection based in the Shared Socioeconomic Pathways with future climate data to study the combined effects on Hydrological response of the watershed. Future rainfall and temperature, for two time periods, were obtained using General Climate Models to provide SWAT with the climatic forcing in order to project water balance variables. The simulation was carried out under two radiative forcing pathways of RCP4.5 and RCP6.0. Model calibration metrics of NSE, R2, and p-factor were $0.88,0.89$, and 0.68 , respectively. Results revealed increases as high as 2.55 and 2.4 for average annual minimum and maximum temperature, respectively, especially during Summer and Winter. Average annual precipitation was estimated to increase up to $11 \%$ under both emission scenarios; however, under severe emissions of RCP6.0, it was projected for two decades earlier. Land use change focused on urbanization dominated the climate changes. Impacts on water balance variables differed seasonally. Results showed surface runoff experienced major changes under both emission scenarios in some months up to 5 times increase. Among the water balance variables, ET as the least dominant pathways for water loss, showed the modest changes with the largest decrease during Fall and Summer. Projection indicated more frequent extreme behavior regarding water balance during midcentury. Discharge was estimated to increase through the year and the highest changes were projected during Summer and Fall with 186.3\% increase in November under RCP6.0. Relying on rainfall for farming along with reduced agricultural landuse (11.8\%) and increased urban area (47\%) and population growth, would likely make the water use efficiency critical. The model demonstrated satisfactory performance, capturing the hydrologic parameters. It thus can be used for further modelling of water quality to determine the sustainable conservation practices, extreme weather events such as hurricane and tropical storms.

Key words: Hydrological Modeling, land use change, Climate Change, , Forested Watershed, , LOCA, Evapotranspiration.

\section{Introduction:}

From different studies and witnessed abnormalities around the globe, it is now clear that climate change has brought and will bring vulnerabilities. $\mathrm{CO}_{2}$ in the atmosphere has set the record in 2018 since preindustrial era (1850-1900) (Poloczanska, Mintenbeck et al. 2018). Some individual sites indicate that the level has been increasing for the year of 2019. Consequently, global mean temperature has been rising 1.5 above preindustrial (1850-1900) era (Poloczanska, Mintenbeck et al. 2018). Other key indicators of the critical situation are Sea Level Rise (SLR) and Sea Ice Extent (SIC); both are the direct consequence of greenhouse gas (GHG) increase in the atmosphere. SLR has hit the record in 2019 of $3.2 \mathrm{~mm} /$ year during the 1993-2019 period and also Arctic extent has been decreasing (Poloczanska, Mintenbeck et al. 2018). On the local scale, the warming has consistent with the weather and climate variabilities related to climate change; North America has been unusually cold due to the crisis (Poloczanska, Mintenbeck et al. 2018). These changes have changed and will continue to change the climate, making the weather harsh. Extreme precipitations, more frequent hurricanes, intense tropical cyclones, unexpected thunderstorms and tornados, sever cold breaks, prolonged droughts, and seasonal timing shifts are expected to be common (Groisman, Knight et al. 2005; Diffenbaugh, Scherer et al. 2013; Emanuel 2013; Diffenbaugh, Swain et al. 2015; Gao, Leung et al. 2015; Sobel, Camargo et al. 2016). These threats not only target human communities but also do threaten ecosystems functionality.

Climate models have proven to be reliable enough to take actions against climate change reverse impacts. A projected hydrological model has the ability to plan for management practices in a given watershed. Hydrological projections have been studied by researchers around the globe at local and global scales. Significant 
changes in hydrological regimes in most part of the land surface of the planet will be likely to occur by midcentury (2050) or they are sensitive to global mean temperature below 2 (Arnell and Gosling 2013). AR4 (Field, Barros et al. 2012) of IPCC reported low confidence on the anthropogenic climate change footprints in flood records, which was due to limited instrumental records in terms of space and time. However, regarding impact on hydrological cycle like precipitation and snowmelt, and earlier spring peak flows, the report showed medium to high confidence which the latter was very likely (Field, Barros et al. 2012; Georgakakos, Fleming et al. 2014). Hydrological projections indicate sensitivity of flood frequency and climate change will be the partial reason for increasing flood likelihood on the global scale (Cisneros, BE et al. 2014). Climate change will adversely change streamflow and water quality and consequently will jeopardize freshwater ecosystems (Cisneros, BE et al. 2014). The projections also reveal medium to high level of confidence in posing risk to potable water (Cisneros, BE et al. 2014).

In Southeast of the US, seasonal drying has been observed for spring, fall, and winter and in summer the soil moisture has increase during 1988-2010 (Georgakakos, Fleming et al. 2014). Although potential evapotranspiration (PET) has projected to increase, evapotranspiration (ET) as the $2^{\text {nd }}$ largest component of the hydrological cycle requires further studies to see possible implication of the causes like soil moisture in future ET trends (Georgakakos, Fleming et al. 2014). Projections for annual runoff and consequent stream flow in the Southeast indicate declines, which is consistent with long-term (multi-seasonal) droughts that are projected for the Southeast (Georgakakos, Fleming et al. 2014).

River floods are more complex to be considered as the direct result of the heavy precipitation and topography, soil moisture, channel condition, and anthropogenic influences are thought to play the key roles (Georgakakos, Fleming et al. 2014). River floods have been decreasing in most part of the Southeast at least $6 \%$ percent per decade (Villarini, Serinaldi et al. 2009; Georgakakos, Fleming et al. 2014). Areas close to the Golf Coast have been hit by hurricanes several times in recent years. Catchment specific characteristics like seasonality and storm frequencies have implications in the flood peaks (Villarini and Smith 2010). Since it is difficult to carry out a reliable projection for very heavy rainfall, it is necessary to study hydrological feedback of the area to the storms. Few studies like Ge Sun et.al., (2013) have studied the impact of climate change on the entire southeast and demonstrated the importance of water supply stress using projections by 2050 . They showed increase in runoff and sediment yield due to increase in erosivity and/or vegetation cover loss. They also stated that climate change and possible future stressor like population growth, land use change, energy security, and policy shift would interact with surface and groundwater availability (Sun 2013).

The Southeast in past has experienced political tensions over water resources (Manuel 2008). Projected warm weather will increase ET, leading to reduced water availability and ground water recharge (Ingram, Dow et al. 2013; Sun 2013; Walsh, Wuebbles et al. 2014). Uptake of soil water by forests is expected to increase, leading to decline in water yield under increased temperature and decreased precipitation projections (Ingram, Dow et al. 2013). Projected population growth and land use change will worsen the situation and pose threat on the economy and unique ecosystems; and land use change in Southeast which ultimately exacerbates the water scarcity, is faster than any other areas in US (Carter, Jones et al. 2014). Future trends derived from projections for 2010-2060, show 5 to $6.5 \%$ decrease in the net water yield for the western part of the Southeast region including Alabama (Sun 2013). Projected temperature extremes are noticeable in the Southeast region. Projections show 4.3 and 7.72 rise by mid-century (2036-2065) and late-century (20712100) under RCP 8.5 respectively (Vose, Easterling et al. 2017). The historical changes for temperature extremes, however, showed insignificant warming of 0.6 (difference between mean of ,1986-2016 and 19011960) for the Southeast, which was the smallest increase over the continental US (Meehl, Arblaster et al. 2012; Vose, Easterling et al. 2017). Projections under RCP 8.5 by mid-century also reveal 40-50 days per year with temperature greater than 32 as a key temperature threshold (Vose, Easterling et al. 2017). For changes in numbers of nights below 0, projections (2041-2070 compared to 1971-2000) show increase of 10-15 days for most the region and more than 20 for the northern part of the Southeast (Katz, Parlange et al. 2003). Southeast is categorized as the second vulnerable to weather and climate disasters in the US for the past three decades (1980-2012); Hurricanes can be considered as disasters for the coastal area and tornados and storms are disasters for inland regions where they are close to the Golf and Atlantic coasts (Carter, 
Jones et al. 2014). Many factors contribute to the climate of the Southeast region including closeness to the Atlantic Ocean and the Gulf of Mexico and El Nino-Southern Oscillation (ENSO), and land falling tropical weather systems (Katz, Parlange et al. 2003). There are few studies that specifically addressed the effects of climate change on the southeast. On the other hand, the scope of studies was the entire Southeast of US and land use change had not been considered to quantify the rapid land use change in the area (Trail, Tsimpidi et al. 2013). Natural hazards like drought, flood, and in general vulnerabilities produced by climate, are results of regional behavior not global (Mahmood, Pielke Sr et al. 2010). Also, it is essential to improve regional projections to determine the mechanisms of the regional forcings and related climate impacts clearly (NRC and CRC 2005). Although, most studies on hydrological future projections have come to the conclusion that water balance components including water yield, surface runoff, ET, baseflow will be affected under in the future under climate scenarios, the hydrological response itself varies depending on region-specific characteristics, topography geography location, and precipitation regimes (Sunde, He et al. 2017). Previous studies have revealed the general impacts of the climate change for the entire Southeast of the US. But they have not used the Coupled Model Intercomparison Projects -Phase 5 (CMIP5) downscaled data with increased robustness and detailed outcome than the Coupled Model Intercomparison Projects -Phase 3 (CMIP3) combined with land use projections. Therefore, in this study, we carried out the investigation on the subbasin scale and with new developed techniques for data preparation. This study provides greater details for a better understanding of the hydrological process, leading in sustainable climate change adaptation. We use SWAT for hydrological modeling and couple it with three representative GCM models in which the data are downscaled using a new developed method called Localized Constructed Analogs (LOCA). In the recent past, researcher have used the same methodology, but with different downscaling method and with predecessors of CMIP5 (Sunde, He et al. 2017; Chen, Marek et al. 2019; Hoyos, Correa-Metrio et al. 2019; Pandey, Khare et al. 2019). Pandey et.al. (2019) have found decline in blue and green water under both RCP4.5 and RCP8.5 pathways for their study area. Comparing different GCMs coupled by SWAT, Sunde et al. (2017) showed decrease in stream flow and increase in ET for their case study. Chen et al. (2017) have investigated land use change and projected $12 \%$ to $20 \%$ decline in crop ET by mid and end of $21^{\text {st }}$ century respectively (Chen, Ale et al. 2017). Impacts of afforestation and deforestation on hydrological response have also been studied (McNulty, Caldwell et al. 2013; Sunde, He et al. 2017; Cecílio, Pimentel et al. 2019). Consistent results have not been an outcome of the impact of forest on water yield (Cecílio, Pimentel et al. 2019). Geographical location of the afforestation in Brazilian Atlantic Rainforest showed small significance regarding impact on the average stream flow; however, the minimum flow was reduced (Cecílio, Pimentel et al. 2019). Longer growing season and increased wildfire likelihood and reduction in stream flow were projected for southeast US forests (McNulty, Caldwell et al. 2013). Hoyos et al. (2019) have investigated the hydrology response to drought and reported that the watershed feedback relies on climatic mechanisms and catchment characteristics. Since climate variables should be calculated to investigate the climate change impact on hydrology of a given watershed, it is necessary to couple improved downscaled GCMs with SWAT (Pandey, Khare et al. 2019). On the other hand, hydrological cycle response is unique for each watershed due to the different factors engaged in the process. Thus, it is important to study hydrologic behavior in a smaller scale with greater details. Therefore, herein, we study the hydrological response of Upper Choctawhatchee Subbasin (UCS) to address the possible hydrological response under different climate and land use scenarios. The goals of the study are i) to establish a robust hydrological model for the UCS, ii) to couple the detailed projections with a new downscaling method and iii) to analyze the response of the UCS regarding future stressors.

\section{Study Area:}

The Upper Choctawhatchee Subbasin (UCS) is in Southeast Alabama. It is a Subbasin of the Hydrologic Unit Code (HUC) of 03140201 (Seaber, Kapinos et al. 1987). The area is in East Golf Coast Plain physiographic section of Alabama. It is heavily forested, mainly Evergreen land cover type (FRSE), based on National Land Cover Database (NLCD) land cover classification derived from Multi-Resolution Land Characteristics 
(MRLC) Consortiums (MRLC-Consortium 2019). The second large land cover is Agricultural Land with 15.4 percentage of the UCS area. The main crops are cotton and peanut. Other crop types are corn, soybean, pecans, and sorghum (Hinson, Rogers et al. 2015). The percentage of all classes of urban land cover adds up to $8 \%$. It comprises of different land cover classes. Table 1 illustrates the main land use and their coverage area. The total drainage area is $3940 \mathrm{~km}^{2}$. The UCS is located between longitudes -86 and -85.26 and latitudes 31 and 31.88. The topographic characteristic of the area can be described as alluvial flood plains, prairies, sharp ridges, and gently rolling hills. Geologic structures are originally made from sediment; these units underlie the Coastal Plain and consist of sand, gravel, porous limestone, chalk, marl, and clay (Hinson, Rogers et al. 2015). According to the Index of Biotic Integrity, the biological stream condition of the subbasin and the Pea River Subbasin (located at the west of the UCS) is as follows: 64\% is rated very poor to fair, $30 \%$ Is rated good and 6\% is rated excellent (O'Neil, Shepard et al. 2006; Hinson, Rogers et al. 2015). Farmers have been using traditional ways of irrigation, thus undeveloped agricultural practices as a sign of lack water management could pose threats to the already-degraded ecosystem. Climate in the region is considered to be sub-tropical, consequently, it is humid with hot summers and mild winters. Annual mean temperature is around 18.5. Average daily temperature for cold time of the day is 18.5 as opposed to 32 as the hottest moment. Average annual precipitation ranges from $1295 \mathrm{~mm}$ to $1422 \mathrm{~mm}$ (USWeatherService 2019). Figure 1 illustrates the area of study.

\section{Methodology}

\subsection{Spatial data}

We incorporated spatial analysis using Geological Information System (GIS) techniques and developed a code (SWATpy) in Python programming language to semi-automate and perform the analyses. The code is under development to fully automate the entire modeling process. Python 3 and ArcSWAT version 2012.10.19 (SWAT v2012, rev.667) were used. Soil, Land use, and elevation data (Digital Elevation Model $(\mathrm{DEM}))$ are in a gridded format. US soil database includes two types of soil data: State Soil Geographic Database (STATSGO) and gridded Soil Survey Geographic Database (gSSURGO) (SoilSurvey 2019). The former is in built in SWAT soil database and the later were derived from United States Department of Agriculture (USDA) (Winchell, Srinivasan et al. 2013). gSSURGO was selected for the modeling due to greater detail and better performance (SoilSurvey 2019). The UCS soil map has more than 250 soil classes. The elevation and land use data sets were derived from US Geological Survey (USGS) and Multi-Resolution Land Characteristics (MRLC) Consortiums, respectively. The Digital Elevation Model (DEM) of 1/3 arcsecond (approximately 10m resolution for the study area) was used. It is a 3DEP (3D Elevation Program) map (U.S.GeologicalSurvey 2017). The data extent is $1^{*} 1$ degree. The land use data set is NLCD2016 in 30 $\mathrm{m}$ resolution (Yang, Jin et al. 2018); and the corresponding 2001-2006 lookup table was used.

\subsection{Hydro-meteorological data}

SWAT uses 5 type of daily weather data as input: precipitation, temperature, solar radiation, wind speed, and humidity (Neitsch, Arnold et al. 2011). For Precipitation and temperature, measured data from weather stations were used. For other climate variables, we used the model's Weather Generator (Neitsch, Arnold et al. 2011). The generated variables are created using statistical data calculated from monthly average values for the climatic variables within the SWAT weather databases (Neitsch, Arnold et al. 2011; Arnold, Kiniry et al. 2013). The data used in this study are daily and span from 1998 to 2013.

Big gaps between Land-based weather station (LBWS) can be problematic (Fuka, Walter et al. 2014). Since we had noticeable gaps between some of the LBWS, two weather data were tested: Climate Forecast System Reanalysis (CFSR) from the National Centers for Environmental Predictions (NCEP) and LBWS data. The preliminary result for latter was better. Therefore, the LBWS data were selected. We believe this is due to the courser resolution of the CFSR data comparing to the distances weather stations. The CFSR 
resolution is $0.5 \mathrm{deg}$ latitude x $0.5 \mathrm{deg}$ longitude (Saha, Moorthi et al. 2010). A few studies have done the same analysis and reached the same conclusion (Dile and Srinivasan 2014; Roth and Lemann 2016). Even though, the distribution of the LBWSs was irregular as opposed to gridded distribution of CFSR data, the land-based data performed better. SWAT assigns one weather station data to each subbasin (closest LBWS to the centroid of a subbasin) (Masih, Maskey et al. 2011; Winchell, Srinivasan et al. 2013). There are two methods to connect LBWS to the subbasins: the centroid method and time dynamic Voronoi tessellation (Neitsch, Arnold et al. 2011; Andersson, Zehnder et al. 2012; Winchell, Srinivasan et al. 2013; Tuo, Duan et al. 2016). The former was utilized which had advantages and disadvantages (Cho, Bosch et al. 2009; Galvan, Olias et al. 2014; Tuo, Duan et al. 2016). Considering the procedure for assigning gauge station in SWAT, we carried out a sensitivity analysis for our original LBWSs and then three LBWSs were removed due to false allocation of the weather data.

The observed streamflow data were derived from the National Water Information System (NWIS) of U.S Geological Survey (USGS). From four stream sites within the UCS, two of them that had representative location and adequate data were selected. The selected sites (Newton (NW) (USGS2361000) and Bellwood (BL) (USGS2361500)) have mean daily discharge data since 1921/12/01. The observed discharge data used for this study spans from 1998 to 2013.

\section{Future climate data:}

A set of benchmark emission scenarios referred to Representative Concentration Pathways or RCPs (Moss, Babiker et al. 2008) are possible development trajectories for the main climate change drivers (Van Vuuren, Edmonds et al. 2011). Research on the multi-gas emission scenarios were the base of the RCPs development (Fujino, Nair et al. 2006; Smith and Wigley 2006; Clarke, Edmonds et al. 2007; Riahi, Grubler et al. 2007; Van Vuuren, Den Elzen et al. 2007; Wise, Calvin et al. 2009). They collectively encompass (extending to year 2100) radiative forcing values from 2.6 to $8.5 \mathrm{~W} / \mathrm{m}^{2}$ relative to year $1750(59,27)$. These scenarios are as follows: RCP2.6, RCP4.5, RCP6, and RCP8.5. RCP 2.6 is a mitigation scenario and its goal is to keep the global mean temperature rise under 2 (Moss, Babiker et al. 2008; Moss, Edmonds et al. 2010; Van Vuuren, Stehfest et al. 2011). The radiative forcing for RCP2.6 increases up to around 3 Watts per square meter $\left(\mathrm{W} / \mathrm{m}^{2}\right)$ before 2100 and then declines (Meinshausen, Smith et al. 2011; Van Vuuren, Stehfest et al. 2011). Under RCP4.5 and RCP6, concentration of GHGs are stabilized (without overshoot) after 2100 (Moss, Edmonds et al. 2010). RCP4.5 stops increasing radiative forcing at $4.5 \mathrm{~W} / \mathrm{m}^{2}$ by year 2100 and the forcing becomes constant afterward (Thomson, Calvin et al. 2011). RCP6 pathway controls the increasing radiative forcing at $6 \mathrm{~W} / \mathrm{m}^{2}$ without exceeding the value afterward (Masui, Matsumoto et al. 2011). GHGs emission increase by around 2060 and then decline till 2100 (64). RCP8.5 assumes high population and slow economic growth which leads to increasing GHGs emissions resulting in radiative forcing as high as $8.5 \mathrm{~W} / \mathrm{m}^{2}$ by end the $21^{\text {st }}$ century and it is assumed to rise afterward (Riahi, Rao et al. 2011). Additional actions are required to halt continuously rising level of GHG concentrations which are due to the growth of global population and economic activities (Pachauri, Allen et al. 2014). These actions are dependent upon the political and socio-economic conditions on the global scale (Van Vuuren, Den Elzen et al. 2007; Van Vuuren, Stehfest et al. 2011). With taking the current global political condition and its possible future pathway into account, we selected the RCP 4.5 and RCP6.0 as moderate and severe pathways, respectively.

The General Climate Models (GCMs) use these RCPs to produce future climate data. The main source of climate projections is the modeling results of the Coupled Model Intercomparison Projects (CMIP3 \& CMIP5) (Sunde, He et al. 2017). Since GCMs' horizontal resolution is low, it is difficult to derive regional scale climate information from them (Flato, Marotzke et al. 2014). In general, GCM results are not reliable for models with resolution less than $200 \mathrm{~km}$ (Meehl, Stocker et al. 2007). Hydrological processes occur on a scale (in order of $10 \mathrm{~km}$ ) at which GCMs (resolution of $1^{\circ}$ to $2.5^{\circ}$ latitude-longitude) cannot provide reliable results (Kundzewicz, Mata et al. 2007; Pierce and Cayan 2016). Moreover, GCMs are not able to capture frequency and magnitude of extreme events (Christensen and Christensen 2007; Fowler, Blenkinsop et al. 2007). Therefore, for important climate variables like precipitation and temperature it is necessary to use higher resolution. Downscaling techniques have been used rigorously to produce 
climate variables from GCMs on the desired scale for hydrological modeling of climate change impact studies (Maraun, Wetterhall et al. 2010; Fu, Charles et al. 2013; Sunde, He et al. 2017). Between two types of the existing downscaling techniques which are dynamical and statistical, we used the statistical downscaling method. Statistical method downscales GCMs' output based on the historical relationship between largeand small-scale conditions (Pierce, Cayan et al. 2014). In this study we used a statistical downscaling called Localized Constructed Analogs (LOCA). LOCA chooses analog days from observed data and applies a multiscale spatial matching scheme to estimate suitable downscaled climate variables (Pierce, Cayan et al. 2014). More realistic regional patterns of precipitation, better estimates of extreme events, and reduced number of light-precipitation days are the advantages of LOCA (Pierce, Cayan et al. 2014). More information on LOCA can be found here: http://loca.ucsd.edu/, (Ficklin and Barnhart 2014).

Considering the complexity of the GCMs, CMIP5 outputs are inevitably biased (Teutschbein and Seibert 2010; Taylor, Stouffer et al. 2012). Bias correction (BC) is the process of transforming GCM outputs using algorithms in order to adjust the outputs (Teutschbein and Seibert 2010; Chen, Marek et al. 2019). Basically, biases are detected by comparing the observation and simulation results and then they are used to correct baseline and projections (Teutschbein and Seibert 2010; Chen, Marek et al. 2019). Bias-corrected inputs for hydrological modeling improve the result, hence bias correction is needed for GCMs output (Wilby, Hay et al. 2000; Pierce, Cayan et al. 2015). LOCA as a downscaling technique improved based on constructed analogs (CA) process contains a bias correction step (Hidalgo Leon, Dettinger et al. 2008; Pierce, Cayan et al. 2014). The BC in LOCA includes 3 steps. First, a preconditioning technique is used to correct the annual cycle and then two different distribution techniques are used, one for temperature and one for precipitation, and finally a frequency-dependent bias correction (FDBC) is used to adjust the sequencing of variation for different time scale, since the sequencing for GCM outputs potentially differ from observed ones (Li, Sheffield et al. 2010; Pierce, Cayan et al. 2015). We obtained and analyzed CMIP5 output the LOCA dataset for three models, CCSM4,GISS-E2-R, and GFDL-CM3, under RCP4.5 and RCP6.0 from Downscaled CMIP5 Climate and Hydrology Projections (https://gdo-dcp.ucllnl.org/) (Schmidt, Ruedy et al. 2006; Donner, Wyman et al. 2011; Gent, Danabasoglu et al. 2011; Taylor, Stouffer et al. 2012; Bureau of Reclamation 2013). The downloaded data are bias-corrected $1 / 16^{\text {th }}$ degree latitude-longitude $(\sim 6 \mathrm{~km} \times 6 \mathrm{~km})$ daily precipitation $(\mathrm{mm} /$ day), and maximum and minimum temperature $(\operatorname{deg} \mathrm{C})$ projections. Hereafter the downloaded dataset, which is downscaled, and bias corrected by LOCA, is referred as "the CMIP5 multimodel ensemble LOCA". The LOCA dataset contains future projections under RCP4.5 and RCP6.0 for 32 GCMs for the conterminous US from 1950 to 2099.

In hydrological projection process using GCMs, their initial condition, future scenarios, and hydrological model incorporate uncertainties to the result (Chen, Brissette et al. 2011). Ouyang et al. (2015) have concluded that different result of the future projections are partially due to the different climate models (Ouyang, Zhu et al. 2015). Considering the numerous numbers of the GCMs and the variability they could cover based on the model skill and independency, we selected the three models to be able to analyze broad extents of changing climate variables within the UCS; in this way we were able to address the uncertainty (Sanderson, Knutti et al. 2015; Sanderson, Knutti et al. 2015; Sunde, He et al. 2017). Locating and Selecting Scenarios Online (LASSO) tool from Environmental Protection Agency (EPA) ( https://lasso.epa.gov/) was used to filter out the selected model from 32 GCMs. Through the different steps of the tool, we have examined climate parameters variabilities with two time periods (annual and seasonal) and selection strategies to reach the goal of three representative models. Models' name, their associated institution, type of experiment, and ensemble member are shown in Table 4. For the ensemble member names, the number after $r$ is the 'realization' number and is used to identify the initial condition. The number after i is 'initialization method indicator' and the number after p refers to model versions with the same perturbed physics (Taylor, Balaji et al. 2011). The listed ensemble members are different only in their initial condition.

\section{Scenario development:}

Two projection period, both under RCP4.5 (moderate) and RCP6.0 (severe) were presented, mid-century (2040-2069) and late-century (2070-2099). The results of hydrological simulation were shown in monthly, 
seasonal, and annual time scales. The seasons were defined as DJF (winter: December, January, February), JJA (summer: June, July, August), MAM (spring: March, April, May), and SON (fall: September, October, November).

SWAT incorporates $\mathrm{CO}_{2}$ to account for its impact on plant water requirements and on level of the potential evapotranspiration (PET) (Neitsch, Arnold et al. 2011). It takes the $\mathrm{CO}_{2}$ concentration amount as a single input value for each subbasin. The $\mathrm{CO}_{2}$ concentration values for the historical and future projections are shown in Table 5. The values are derived from Meinshausen, Smith et al. (2011).

Projected population for the conterminous US indicates significant increase in demand for food, energy, and urban development (Sohl, Sayler et al. 2014). From 2001 to 2011, the Southeast region (AL, AR, FL, GA, KY, LA, MS, NC, SC, TN, and VA) has lost more than 100 and $1400 \mathrm{sq}^{2}$ agricultural land and forest, respectively, and gained $600 \mathrm{sq}^{2}$ developed land cover (Sleeter, Loveland et al. 2018). For UCS and Pea and Yellow River Subbasin, farming land decreased 27.21\% and urban area increased $42.55 \%$ from 1992 to 2011 (Hinson, Rogers et al. 2015). Regarding land use condition in the future, there have been few studies (national US and global scale) based on different scenarios including Special Report on Emission Scenarios (SRES) (96) , RCP, and Shared Socioeconomic Pathways (SSP) (95) of Intergovernmental Panel for Climate Change (IPCC) (Nakicenovic, Alcamo et al. 2000; Wear 2011; Sohl, Sayler et al. 2014; Sohl, Wimberly et al. 2016; Riahi, Van Vuuren et al. 2017; Sleeter, Loveland et al. 2018). Sohl et al. (2014) using different land use forecasting model, has predicted $22.9 \%$ to $61 \%$ increase in urban land cover for conterminous US by the year 2050. They projected noticeable loss of natural covers which was due to expansion of anthropogenic land uses. The fourth National Climate Assessment reported 50\% and $80 \%$ increase in urban land use allocation by 2100 under SSP2 and SSP5 respectively with 2010 land use condition as the baseline (Sleeter, Loveland et al. 2018). To account for these changes, we obtained and analyzed projected land covers for each decade till 2100 from Fourth National Climate Assessment dataset through Global Change Explorer (GCX) ((GCX) 2020). These maps are based on SSP scenarios with 19 land cover classes (Bierwagen, Theobald et al. 2010; (EnvironmentalProtectionAgency) 2017). One possible caveat though, is that there is not much agreement between different forecasting models and they appear to be at the beginning stage of development (Sohl, Wimberly et al. 2016). Future projection results for all models in this study were presented in monthly, seasonal, and annual average and compared to the historical result to analyze the future hydrological condition within the UCS. Then we did the same comparison for SWAT simulation, mainly discharge. Corresponding land use projections to projection periods (mid-century and end-century) were used in SWAT modeling to simulate the discharge and evapotranspiration (ET). Finally, we used box plots to show the changes of the climate and hydrological variables.

SWAT: For this study we used Soil \& Water Assessment Tool (SWAT). SWAT is assemblages of mathematical equations representing different parts of hydrological cycle including movement, fate, and transport of water, sediments and nutrients in and on soil, through groundwater, and in river streams and reservoirs (Arnold, Srinivasan et al. 1998; ASABE Jun. 2017). The development of the model started in early 1990s and it has been evolving by USDA (United States Department of Agriculture) agricultural Research Service (ARS) (Gassman, Reyes et al. 2007; Arnold, Moriasi et al. 2012). It is a process based and semi-distributed continuous-time river basin scale model (Arnold, Kiniry et al. 2011; Arnold, Moriasi et al. 2012). It has been written in Fortran language including more than 310 subroutines representing different parts of the hydrological and bio-geochemical processes (Arnold and Fohrer 2005; Arnold, Kiniry et al. 2011). It was originally developed to evaluate water resources management and Nonpoint Source (NPS) pollution in large river basin (Arnold, Moriasi et al. 2012). It has proven to be effective for its purposes and computationally efficient and can be used for long term continuous simulation including climate change impact studies (Gassman, Reyes et al. 2007; Arnold, Moriasi et al. 2012). It operates on a daily time step and outputs daily, monthly, and yearly results (Gassman, Reyes et al. 2007; Arnold, Moriasi et al. 2012). SWAT splits a watershed into subwatersheds that are further split into hydrologic response units (HRUs) (Gassman, Reyes et al. 2007; Arnold, Moriasi et al. 2012). HRUs are nonspatial units and unique combination of homogeneous land use, soil, slope and management characteristics (Gassman, Reyes et al. 2007; Arnold, Moriasi et al. 2012). This gives SWAT the capability to model surface runoff, infiltration, soil water movement, ET, 
in-stream transformations, sediment movement, canopy interception, plant uptake, and nutrients circulation including biogeochemical processes at HRU level (Neitsch, Arnold et al. 2011). Main components of a SWAT model for a given watershed are weather, hydrology, erosion/sedimentation, plant growth, nutrients, pesticides, agricultural management, stream routing and pond/reservoir routing (Arnold and Fohrer 2005). Simulation in SWAT has two parts, land phase and routing phase; in land phase, the amount of water, sediment, nutrient, and pesticide loadings are regulated into the main channel in each subbasin, and in the routing phase, in- stream processes including water movement, sediment transport and the nutrients loading are simulated (Neitsch, Arnold et al. 2011; Arnold, Moriasi et al. 2012). In SWAT, Water balance is the base of all the processes and the hydrological cycle is climate driven, thus, SWAT requires precipitation, minimum and maximum temperature, solar radiation, relative humidity, and wind speed in daily time scale (Arnold, Moriasi et al. 2012).

SWAT uses equation (1) to simulate water balance (Arnold, Srinivasan et al. 1998; Neitsch, Arnold et al. 2011):

$$
S W=\mathrm{SW}_{0}+\sum_{i=1}^{t}\left(R_{\mathrm{day}}-Q_{\mathrm{surf}}-E_{a}-w_{\mathrm{seep}}-Q_{\mathrm{gw}}\right)
$$

where $\mathrm{SW}$ and $\mathrm{SW}_{0}$ are soil water content for beginning and end of the model, respectively. $\mathrm{t}$ (day) is time. $R_{\text {day }}$ is rainfall; $Q_{\text {surf }}$ is surface runoff; $E_{a}$ is evapotranspiration; $w_{\text {seep }}$ is percolation to vadose zone, and $Q_{\mathrm{gw}}$ is return flow amount, and all variables are in mm (Arnold, Srinivasan et al. 1998; Neitsch, Arnold et al. 2011).

Water yield as part of subbasins blue water is the amount of water after leaving HRUs and entering the main channel is calculated with equation (2) (Neitsch, Arnold et al. 2011; Arnold, Kiniry et al. 2013; Veettil and Mishra 2016):

$$
W Y L D=Q_{\text {surf }}+Q_{\text {lat }}+Q_{\mathrm{gw}}-\text { tloss }- \text { Pond abstractions }
$$

where WYLD is the amount of water yield, $Q_{\text {surf }}$ is surface runoff, $Q_{\mathrm{gw}}$ is return flow amount, $Q_{\text {lat }}$ is the amount of lateral flow, tloss is transmission losses, and the abstracted water from the pond; all variables are in mm (Arnold, Kiniry et al. 2013; Chanapathi, Thatikonda et al. 2018; Pandey, Khare et al. 2019).

In SWAT surface runoff can be estimated in two ways: SCS (Soil Conservation Service) runoff curve number method (USDA-SCS, 1972) and the Green \& Ampt infiltration method (1911) (Neitsch, Arnold et al. 2011)(45). We used the former. Equation (3) is SCS runoff curve number method (Arnold, Srinivasan et al. 1998; Neitsch, Arnold et al. 2011):

$$
\begin{array}{cc}
Q_{\text {surf }}=\frac{\left(R_{\text {day }}-0.2 S\right)^{2}}{\left(R_{\text {day }}+0.8 S\right)} & R_{\text {day }}>0.2 S \\
Q_{\text {surf }}=0 & R_{\text {day }} \leq 0.2 S
\end{array}
$$

where $Q_{\text {surf }}$ is surface runoff; $R_{\text {day }}$ is rainfall; and $\mathrm{S}$ is retention parameter. $0.2 \mathrm{~S}$ is estimated as the initial abstraction including surface storage (Neitsch, Arnold et al. 2011). Retention parameter varies through the watershed and time owing to changes in soil, land use and management (Neitsch, Arnold et al. 2011). S is estimated as follows:

$$
S=254\left(\frac{100}{\mathrm{CN}}-10\right)
$$


where $\mathrm{CN}$ is the curve number which is adjusted for different soil moisture level and slope (Neitsch, Arnold et al. 2011).

For surface runoff equation 3 was used. For flow routing the variable storage coefficient method were used (Williams 1969; Neitsch, Arnold et al. 2011). Since our modeling required simulation of $\mathrm{CO}^{2}$ climate change effects, the Penman-Monteith method was used for calculation of potential evapotranspiration(Monteith 1965; Allen 1986; Allen, Jensen et al. 1989). Actual evapotranspiration (AET) the was calculated by procedure established by Richtie (1972) (Ritchie 1972). The UCS was delineated into 54 subbasin and 1821 HRUs. 'SWAT2012 rev64' version was used to perform the modeling.

\section{Calibration :}

calibration can be manually done or through a combination of manual and auto calibration procedures (Moriasi, Wilson et al. 2012). Our approach to calibrate and validate was the later through a split-sample strategy (Moriasi, Wilson et al. 2012). To evaluate the performance of the model we have first carried out a sensitivity analysis (SA) manually and then using SWAT Calibration and Uncertainty Procedures (SWATCUP) to filter out insensitive parameters to reduce the computational workload of the calibration (Gupta, Sorooshian et al. 1999; Saltelli, Tarantola et al. 2004; Abbaspour, Vejdani et al. 2007; Ghoraba 2015). Sensitivity analysis is to estimate how much model outputs change with respect to each model parameter (input) change (Saltelli, Tarantola et al. 2004; Arnold, Moriasi et al. 2012). First a set the parameters were selected according to UCS hydrologic characteristics and the literature (Abbaspour, Yang et al. 2007; Joh, Lee et al. 2011; Sudheer, Lakshmi et al. 2011; Arnold, Moriasi et al. 2012; Abbaspour, Rouholahnejad et al. 2015; Osei, Amekudzi et al. 2019; Qiu, Shen et al. 2019). Then using one-factor-at-a time sensitivity analysis initial parametrization was carried out and parameters were optimized and their initial ranges were predicted (Morris 1991; Green and Van Griensven 2008; Abbaspour, Rouholahnejad et al. 2015). After a set of manual calibration using first set of the parameters, we used SWAT-CUP to modify the selected parameters and perform sensitivity and uncertainty analysis (Arnold, Moriasi et al. 2012). We used the Sequential Uncertainty Fitting version algorithm (SUFI2) within SWAT-CUP (Abbaspour, Johnson et al. 2004; Abbaspour, Yang et al. 2007). The SUFI2 is based on the invers modeling and is to estimate parameters using observed data (Abbaspour, Johnson et al. 2004; Abbaspour, Yang et al. 2007). In other words, it uses initial large parameter uncertainty and through steps, decrease the uncertainty until the uncertainty range falls within a range/band called 95\% Prediction Uncertainty (95PPU) (Abbaspour, Johnson et al. 2004; Abbaspour 2015). SUFI2 uses a global search approach to carry out optimization and uncertainty analysis and it can handle many parameters (Abbaspour, Johnson et al. 2004; Abbaspour 2015). For accuracy quantification of the model, our objective function includes Nash-Sutcliffe Efficiency (NSE), Coefficient of Determination $\left(\mathrm{R}^{2}\right)$, Percent Bias (PBAIS), RMSE-observations standard deviation ratio (RSR) (Nash and Sutcliffe 1970; Gupta, Sorooshian et al. 1999; Legates and McCabe Jr 1999; Moriasi, Arnold et al. 2007). The metrics for satisfactory thresholds were selected based on the literature (Santhi, Arnold et al. 2001; Moriasi, Arnold et al. 2007; Abbaspour, Rouholahnejad et al. 2015). Table 6 shows the objective function and the thresholds of the metrics and final results for calibration and validation period. Following are the formulas used for these metrics.

$$
\begin{aligned}
& N S E=1-\left[\frac{\sum_{i=1}^{n}\left(Y_{i}^{\text {obs }}-Y_{i}^{\text {sim }}\right)^{2}}{\sum_{i=1}^{n}\left(Y_{i}^{\text {obs }}-Y^{\text {mean }}\right)^{2}}\right] \quad, \quad-\infty<N S E \leq 1 \\
& R^{2}=\left[\frac{\sum_{i=1}^{n}\left(Y_{i}^{\text {obs }}-Y_{i}^{\text {mean }}\right)\left(Y_{i}^{\text {sim }}-Y^{\text {simmean }}\right)}{\left[\sum_{i=1}^{n}\left(Y_{i}^{\text {obs }}-Y_{i}^{\text {mean }}\right)^{2}\right]^{0.5}\left[\sum_{i=1}^{n}\left(Y_{i}^{\text {sim }}-Y^{\text {simmean }}\right)^{2}\right]^{0.5}}\right]^{2}, \quad 0 \leq R^{2} \leq 1 \\
& P B A I S=\left[\frac{\sum_{i=1}^{n}\left(Y_{i}^{\text {obs }}-Y_{i}^{\text {sim }}\right) \times(100)}{\sum_{i=1}^{n}\left(Y_{i}^{\text {obs }}\right)}\right] \quad, \quad-\infty<P B A I S<+\infty
\end{aligned}
$$


$R S R=\frac{\left[\sqrt{\sum_{i=1}^{n}\left(Y_{i}^{\text {obs }}-Y_{i}^{\text {sim }}\right)^{2}}\right]}{\left[\sqrt{\sum_{i=1}^{n}\left(Y_{i}^{\text {obs }}-Y^{\text {mean }}\right)^{2}}\right]} \quad, \quad 0 \leq R S R<+\infty$

where $Y_{i}^{\text {obs }}$ is the $i$ th measured stream flow; $Y_{i}^{\text {sim }}$ is $i$ th simulated stream flow; $Y^{\text {mean }}$ is the mean of observed stream flow data; $Y^{\text {simmean }}$ is the mean of simulated data, $\mathrm{n}$ the total number of observations.

NSE value between 0.0 and 1 is considered acceptable with 1 being the optimal value indicating the plot of observed versus simulated fits perfectly (Nash and Sutcliffe 1970; Moriasi, Arnold et al. 2007). For $\mathrm{R}^{2}$, the higher the value the lesser the error variance and values greater than 0.5 are considered to be acceptable (Santhi, Arnold et al. 2001; Moriasi, Arnold et al. 2007). Negative PBIAS means overestimation and positive PBIAS means underestimation, with 0 being the optimal value. RSR ranges from 0.0 to a positive large number, with 0.0 being the optimal condition meaning the RMSE is zero. The lower RSR, the lower residual variation, indicating better model performance (Moriasi, Arnold et al. 2007). NSE, $\mathrm{R}^{2}$, and RSR are unitless and PBAIS has the unit of the constituent being evaluated which for our case is $\mathrm{cms}\left(\mathrm{m}^{3} / \mathrm{s}\right)$. The global sensitivity analysis (where all parameters are allowed to change through analysis) were carried out through SWAT_CUP to prioritize the most responsive parameters and remove parameters with smaller sensitivity from further sampling (Abbaspour, Yang et al. 2007). Through the SA, a multiple regression analysis was used to determine the parameter sensitivity statistics (t-stat and p-value) (Abbaspour 2015). t-stat and p-value were used to describe the relative significance and significance of sensitivity, respectively (Chanapathi, Thatikonda et al. 2018). Sensitive parameters correspond to larger absolute t-stat values among the parameters and to smaller p-values (close to 0; commonly accepted threshold is 0.05) (Abbaspour 2015). The SA results are shown in Table 7. Based on the sensitivity analysis the following parameter were identified as responsive: SOL_AWC (Available water capacity of the soil layer), RCHRG_DP (Deep aquifer percolation fraction), CH_K2 (Effective hydraulic conductivity in main channel alluvium), SLSUBBSN (Average Slope Length), ESCO (Soil evaporation compensation coefficient), GWQMN (Threshold water level in the shallow aquifer for the base flow), and ALPHA_BF (Baseflow alpha factor). Table 8 shows final parameters and their fitted values. It is worth to mention that the SA result is the prediction of the average changes of the objective function being produced by changes in a given parameter as other parameters are also changing (Khalid, Ali et al. 2016). p-factor and r-factor were also considered for SUFI2 performance evaluation as well as measuring the goodness of calibration (Abbaspour, Johnson et al. 2004; Abbaspour, Yang et al. 2007). pfactor is the percentage of observations covered by the 95PPU and r-factor is the ratio of the 95PPU average thickness and the standard deviation of the observations (Abbaspour 2015; Abbaspour, Rouholahnejad et al. 2015). The extent from $2.5 \%$ to $97.5 \%$ of the cumulative distribution of the simulated variable resulting from the Latin hypercube sampling is 95PPU (Abbaspour, Johnson et al. 2004; Abbaspour, Yang et al. 2007; Abbaspour, Rouholahnejad et al. 2015). p-factor ranges from 0 to 1; p-factor greater than 0.7 means acceptable goodness of fit; r-factor varies between 0 and infinity; here r-factor less than 1.5 was considered satisfactory (Abbaspour, Johnson et al. 2004; Abbaspour, Yang et al. 2007; Abbaspour 2015; Abbaspour, Rouholahnejad et al. 2015). Table 6 shows the goodness of fit metrics. The selected parameters were used to calibrate SWAT at two USGS site (Newton (USGS2361000) and Bellwood (USGS2361500)) for subbasins 29 and 52, respectively. Observed data from the later site is used for SA and uncertainty analysis. The number of simulations was 450 with 4 iteration. SWAT was performed for period from 1998 to 2013. From 1998 to 2000 was considered as warm up; from 2001 to 2010 was the calibration period and from 2010 to 2013 was the validation period. Given the final values for the model performance metrics (Table 6) and the accepted thresholds, it was determined SWAT stream flow estimation for the UCS was efficient. Figure 2 shows the calibration result for both calibration (2001-2010) and validation period (2011-2013). 


\section{Results and Discussion:}

The CMIP5 multi-model ensemble LOCA results for precipitation and temperature during baseline period show consistency with the observed values (Figure 3). Between the 3 models, GFDL-CM3 has the closest distribution to the observed precipitation with the $6.8 \%$ median difference and the closest number of outliers. The $25^{\text {th }}$ percentile for the observation and GFDL-CM3 are 71.4 and 74.68 respectively. $75^{\text {th }}$ percentiles are the same (148.3). Therefore, it indicates similar distribution. Figure 3b illustrates the temperature distribution for the observed and baseline period. It represents quiet similarity, especially for model GFDLCM3, where the distance is between $25^{\text {th }}$ and $75^{\text {th }}$ percentile and the whiskers' length are the same. The median difference of models (CCSM4, GFDL-CM3, GISS-E2-R) from the observed ones are $4.2 \%, 2.6 \%$, and $4.7 \%$ respectively. We also compared the baseline ET from the climate data with the observation period (Figure 3c). Figure 3c also demonstrates similar distribution from $25^{\text {th }}$ to $75^{\text {th }}$ percentile from all dataset. However, upper whiskers for the observation is longer. This difference has no implication on the study, since here, we are not focused on extreme weather situation.

Average maximum and minimum temperature has important repercussions on hydrological implications. Figure 4 and 5 illustrate temperature behavior on daily and seasonal base, respectively. Figure 4 represents monthly average of basin-wide daily maximum temperature (Figure4b), monthly average of basin-wide daily minimum temperature (Figure 4c) and monthly average of basin-wide daily temperature (Figure 4a). For average temperature (Figure 4a) models match the observed average temperature, from mid-March to June (Spring) and from mid-September to mid-November (Fall). For Winter (DJF) and Summer (JJA), however, there are differences up to 1 . This trend is the same of maximum temperature (Figure 4b) and minimum temperature (Figure 4c). However, the discrepancies for maximum temperature during Summer (the peak of the graph) and for minimum temperature during Winter (the legs of the graph) are more noticeable. This behavior indicates the more extreme the temperature, the more the difference between the models and the observed data. This also can be seen in daily temperature representation of the subbasin (Figure 5). On the figure, intensified wiggling behavior of the graphs at the troughs and sometimes at the peaks supports the idea. This specially is more obvious in months of December and January.

Figure 6 shows the monthly average of precipitation, ET, water yield, and surface runoff for 10 year for both the beasline and observed period. From mid-March to mid-June, and September and November, the average observed rainfall is the same as the models prediction with negligible differences. During Summer and Winter, however, there exist some discreppencies. These discrepencies could be attributed to the model baises. As SWAT model uses these model results as climate data, the baises can be projected to the simulated hydrological results such as ET, water yield, and surface runoff. Model predictions for ET (Figure 6b) match with the observed data except during summer with small differnces up to $8 \%$ in July. Highest level of water yield occurs during the month March (Figure 6c) where the differnces with the model predictions is around 13\%. During Spring, Summer, and Fall models perdict the amount of average water yield close to the observed data. Since surface runoff amount and water yield are linked, the yearly pattern of surface runoff follows the water yield pattern. Surface runoff is understimated. For example in March when the highest amount of surface runoff happens through the year, the models predictions is 17\% low for CCSM4 and GISSE2-R and 11\% low for GDFL-CM3. This difference is due to land use changes through the time period. Therefore, it indicates the biases of the land use map. In this study, we have not looked for extreme events that partially acount for these biases. Thus, considering the different source of inevitable baises it can be concluded that the results based on the models are reliable

\section{Future climate and hydrological condition:}

Observed annual average percipitation in UCS for observation period is $1440 \mathrm{~mm}$. For the omission scenarios (moderate and severe) and perojected future time period (mid-century and late-century) considered in this study, annual average rainfalls vary from $1486 \mathrm{~mm}$ to $1569 \mathrm{~mm}$ (table 9). Average annual maximum and minimum temperature for baseline period are 13 and 26 respectively. The projected average annual maximum and minimum has increases ranging $0.98-2.4$ and 1.55-2.55, respectively. 
Figure 9 demonstartes the monthly behavior of the projected tempertaure (average, maximum, and minimum) thruogh a year for the entire simulation period (2040-2099). The projecte maximum and minimum temperature shifts above with increases up 3 in June, July, and August during mid-century. There are not noticeable changes between moderate and sever emission scenarios for mid-century, except in summer, where changes are up 1. For the late-century period, however, changes are significant (Figure 9 lower panel). Projected increase for RCP6.0 is doubled compared to the projected increase in temperature under RCP4.5 during late century. For both mid and late century temperature increases for Spring and Fall is not as high as increases in Summer and Winter. This indicates a general warming weather with hotter Summer and Winters that could potentially lead to seasonal time shifting and early snow melts and consequently changes in hydrological cycle in UCS. The annual trend of average, maximum, and minimum temperature behavior shown in Figure 10 supports these changes towards the end of the century. The upper panel shows average annual temperature under RCP4.5 and RCP 8.5. The regression line under severs emission scenarios are steeper indicating more increase as we approach towards the end of the century. Maximum and minimum temperature (the mid and lower panel on Figure 10) also have the same trend. These changes have been quantified in Table 9. Maximum and minimum temperature is projected up to $10 \%$ increase by 90 s under moderate scenario and $30 \%$ increase under sever scenarios compared to baseline period. Table 9 also reflects decadal percent change of rainfall. Based on the models and under moderate scenarios, annual rainfall is projected to increase slightly (Figure 11). However, under sever scenarios no pattern was found. For instance, average precipitation for 40s under RCP 4.5 is projected to decrease $6.33 \%$ and $1 \%$ increase during $90 \mathrm{~s}$ compared to baseline period. Under RCP6.0, however, for 40s, precipitation change is projected to be $6.8 \%$ decrease and for $90 \mathrm{~s}$ is $8.45 \%$ increase. This pattern implicates the wiggling behavior of the precipitation which can implicate extreme precipitation.

\section{Annual and seasonal impacts of future climate on water regime:}

To obtain data required for future water regime, the CMIP5 multi-model ensemble LOCA was integrated with SWAT model. We then derived precipitation, surface runoff, water yield, ET, and discharge for Bellwood (USGS2361500) monitoring point. We analyzed the data at monthly, seasonal, and annual scales (Figure 10-13). Table 10 represents the projected mean annual changes to hydrological components for the entire simulation period and each decade. Mean annual change to the discharge at Bellwood station has an increase of $30.45 \%$ under moderate scenario and $29.67 \%$ increase under the severe scenarios during the entire simulation period. Similarly, mean annual surface runoff during the period has significantly increased with $337.4 \%$ and $325.66 \%$ under moderate and severe scenarios, respectively. Water yield also has shown increase of $18.34 \%$ and $18.08 \%$ under moderate and severe scenarios through the entire period. Slight decreases of $0.8 \%$ under moderate scenario and $2.46 \%$ under severe scenario were observed to mean annual ET during the entire simulation.

Table 10 indicates the simulated mean annual changes to water balance components for mid-century and latecentury period. During mid-century mean annual discharge at Bellwood station was estimated to increase by $24.2 \%$ under RCP 4.5 and $32.93 \%$ under RCP6.0. for late century. However, the mean annual discharge at the station shows $36.72 \%$ increase under RCP 4.5 and $26.4 \%$ increase under RCP6.0. Under the severe scenario, despite the increased urbanization, the discharge amount at the station is projected to decrease towards the end of the century. It can be suggested that the last decade of water balance variables has been affected dramatically (Table 10). Average annual surface runoff during the mid-century is estimated to increase by $286.3 \%$ under RCP 4.5 and $315.5 \%$ under RCP6.0. Mean annual surface runoff continues to increase during the late-century by an average increase of $388.5 \%$ under moderate scenario and $335.9 \%$ under the severe emission scenarios. These changes indicate the significant impact of the land use change on water balance variables. Increases to mean annual water yield were observed under both scenarios of moderate and severe emissions by $12.55 \%$ and $21.42 \%$ during mid-century. During late-century, average annual water yield is expected to increase by $24.14 \%$ under RCP4.5. For RCP6.0, however, average annual water yield is estimated to increase by $14.73 \%$ compared to baseline period. Increase in mean annual water yield under RCP6.0 compared to the increase under RCP4.5 is much smaller during the late-century. This is partially due to the dramatic drop of the hydrologic components during the 90s. Unlike the other variables, slight 
decreases occur to mean annual ET during the mid and late century. For mid-century, a decrease of $0.63 \%$ and $0.01 \%$ respectively under the moderate and severe scenarios, is estimated. During late-century, average annual ET decreases further with $0.95 \%$ and $4.92 \%$ under RCP 4.5 and RCP6.0, respectively.

Figure 10 shows the mean annual trend of water balance variables (surface runoff, water yield, and ET) during the simulation period based on the models and under the scenarios. The regression line for the surface under both scenarios indicate the increase during the entire simulation period. For water yield under moderate scenario the regression lines for all models are slightly steep. The regression slope, however, increases under the severe scenario. Annual trend towards end of the century, shows obvious decrease for ET under sever emission scenarios.

Basin-wide monthly average of the hydrological components is informative in investigating the water balance behavior of the watershed. The hydrological response to projected climate data in UCS changed for each month. Table 11 and Figure 11 illustrate these changes based on the models under both scenarios. During mid-century, under moderate GHG emission the largest changes to precipitation is projected in May (during flooding season) with increase of $48.5 \%$ compared to mean rainfall in the same month during the baseline period. For January, February, and March, it increases 18.9\%, 22.6\%, and 27.4\%, respectively. The largest decrease in rainfall, however, is estimated in August and October with 23\% and 26.7\% respectively (RCP4.5, Mid-century). During the late-century under RCP4.5, the largest increase and decrease are projected in March with 36.1\% and in August with 26.1\%, respectively. For the severe emission scenario, the largest rainfall increase and decrease during mid-century are in January (41.8\%) and December (21.1\%), respectively. For the late century, however, precipitation decreases overall. The largest increase is expected to happen in September (29.9\%) and the largest decrease in October (39.2\%). Overall, August, October, and December are expected to be drier and January, March, and May are expected to be significantly wetter through the entire simulation period under both scenarios (Table 11 and Figure 11). Similar to mean annual behavior of surface runoff, monthly estimates are also projected to increase dramatically. Under both scenarios, June has the highest increase of up to 5 times baseline period in monthly basin-wide surface runoff. The second highest increase is expected to happen in January with up to 4 times of the baseline period. The smallest increases in monthly mean surface runoff is projected in December with the lowest increase under RCP6.0 during late-century $(36.2 \%)$ (Table 11 and Figure 11). Monthly behavior of water yield amount differs from rainfall and surface runoff. Under RCP4.5, overall water yield is projected to be higher than that of mid-century. The largest changes under the moderate scenario is estimated in February $(+58.6 \%)$ and March $(+62.1 \%)$ during late century and in June $(+42.9 \%)$ and July $(+44.4 \%)$ during mid-century (RCP4.5). Under the moderate scenario water yield is estimated to decrease during mid-century in December by $12.4 \%$ and in August by $6.3 \%$. Mean water yield for each month indicates different behavior under the sever emission scenario than expected. Under RCP6.0 and during mid-century, January and June, and October have the increase of $58.4 \%, 62.7 \%$, and $53.7 \%$, respectively. Through the late-century, however, November has the largest increase of $99.4 \%$ in water yield amount. Under RCP6.0, water yield decreases only in December though the entire simulation period (Table11 and Figure 11). Overall ET is expected to decrease slightly. For all months mean ET drops except for April and May. Under both scenarios the largest decrease is estimated in November with close to $20 \%$ drop. From the Figure 11, one can notice the level of decrease in ET during Summer and Fall. Monthly discharge projection is shown in Figure 12 and Table 11. Under both scenarios discharge is estimated to decrease in April and December at Bellwood station with the largest drop of $31.2 \%$ in December during the mid-century under sever emissions. In other months, discharge is expected to increase. During the mid-century, the largest increase is observed in July (106.7\%) and September (115.7\%) under RCP4.5 and RCP6.0, respectively. During the late-century, February, July, and November have almost the same discharge under the moderate emissions. For the severe emission conditions, however, September and November have the highest increase of $133.7 \%$ and $186.3 \%$, respectively. The discharge projections indicate increases in the months in which rainfall is expected to decrease. This can be attributed to the land use change.

Seasonal variations are also expected in hydrological response to future climate data. Interquartile range (IQR) can be used to express this variability (Figure 13). Outliers can be attributed to extreme weather. 
Also, larger IQRs indicate more frequent severe weather. For Spring precipitation during the simulation period, under moderate emissions, the largest IQR ranging from $-27.1 \%$ to $46.9 \%$ is projected at the end of mid-century (70s); under sever emissions the largest IQR ranging from $-40.4 \%$ to $34.8 \%$ is estimated at the beginning of the mid-century (40s). Under RCP4.5 the medians for percent changes increase through the mid-century. Through the late-century, however, the medians for each decade and their IQR show modest changes. This means the most frequent extreme rainfall in Spring is expected during 60s under moderate emissions. These extreme behaviors, however, is expected 2 decades earlier (40s) under the severe emissions. Under RCP6.0, the medians increase from $10.2 \%$ to $33.2 \%$ during the mid-century. Under RCP6.0, medians drop at the start of the late-century and then fluctuate during the last century meaning that Spring rainfall peaks in 80 s with the same frequency behavior. Under moderate emissions 50s has the wettest Spring and 80 s has the driest. Under severe emissions, 60 s and 70s have the wettest and driest Spring, respectively (compared to the baseline period). IQR ranges for Summer rainfall are noticeably smaller than that of Spring, meaning smaller changes for Summer rainfalls. Overall IQR under RCP6.0 is longer indicating more changes (decrease and increase) under severe emissions. Moderate emissions, however, reflects more outliers indicating greater likelihood for heavy rainfalls during Summer. Under RCP4.5 the largest IQR ranging from $-21.9 \%$ to $28.8 \%$ occurs at the start of late-century (70s), making the decade with wettest Summer (compared to baseline) under moderate emissions. The driest Summer is expected to happen at the beginning of the midcentury under RCP4.5. Under RCP6.0 the largest IQR ranging from $-13.2 \%$ to $29 \%$ is expected at the end of mid-century $(60 \mathrm{~s})$ making the period with wettest Summer compared to the baseline. Under RCP6.0, UCS is expected to experience the driest Summer in the middle of late-century period (80s) with the IQR ranging from $-24.9 \%$ to- $8.2 \%$. Similar to Summer rainfall, Fall rainfall also has larger overall IQR under RCP6.0 than RCP4.5, indicating more changes (decrease and increase) under sever emissions.

Under RCP4.5, very small changes are projected to happen to medians during Fall. Under RCP6.0, however, medians increase during the entire simulation period after large drop in the start of the mid-century. Under RCP4.5, the largest IQR is projected during 50s ranging from $-23.3 \%$ to $34.9 \%$ change compared to baseline mean Fall. 70s also shows the same variations. However, the smallest IQR ranging from $-19.5 \%$ to- $5.1 \%$ (under RCP4.5) is estimated during 60s where change variations indicate noticeable number of outliers meaning, strong Fall precipitations compared to baseline period. Under severe emissions, the largest IQR for Fall precipitation occurs in the end late-century (90s) ranging from $-12 \%$ to $51.2 \%$. This variation is followed by 50s IQR ranging from $-47 \%$ to $10.6 \%$. Big portion of the 90 s' IQR indicates increase, but for $50 \mathrm{~s}$ a decrease is observed. This makes the end of the late-century to have wettest Fall and middle of the mid-century to have the driest Fall (under RCP6.0). Early late-century is projected to have the smallest range changes (IQR ranging from $-15.7 \%$ to $12.2 \%$ ) under RCP6.0. Projected Winter rainfall has the shortest IQRs (smallest changes) compared to the other three seasons (both emission scenarios). For both scenarios, during the entire simulation period, IQRs and medians fall below zero line, meaning decreased amount of precipitation during Winter. More outliers under RCP4.5 indicates more extreme changes under moderate than sever scenario during Winter. Under RCP4.5, medians increase towards the end of century, starting from $-21.7 \%$ and ending at $-1.9 \%$. This indicates overall less changes towards the end the simulation period. Under RCP4.5, the largest IQR for Winter rainfall is projected during the late-century (80s) ranging from $-32.9 \%$ to $18 \%$ with the median of $-27.7 \%$ (close to the $25^{\text {th }}$ percentile). Under moderate emission the smallest variation is projected to be during the end of the late century (90s) with IQR ranging from $-16.5 \%$ to $1.2 \%$ (median of $-1.9 \%$ ). Under sever emissions, however, end of the late-century period has the largest IQR ranging from $-7.9 \%$ to $38.7 \%$ with median close to $25^{\text {th }}$ percentile, making the decade wettest for the Winter rainfalls. The smallest variations of Winter precipitation are estimated to occur at the start of the late century (70s). the direst Winter under severe emissions is projected to end of the mid-century (60s) where the median is $-21.5 \%$ (figure 13 ).

Comparing the percent change variations for projected precipitation under both scenarios shows the largest changes in Summer and Winter when switching from RCP4.5 to RCP6.0. similar results were observed by Sunde et al. (2017). Surface runoff variations under future climatic data, shows dramatic changes (figure 13). For all seasons and under both scenarios, surface runoff is projected to increase up to several folds. For Spring 
surface runoff, under RCP4.5, the largest IQR is expected by end of the mid-century (60s) ranging from $76.9 \%$ to $526.5 \%$. The second largest variation is estimated in middle of the late-century period ( $80 \mathrm{~s}$ ) ranging from $155.22 \%$ to $601.7 \%$ (under RCP4.5). The smallest variation (IQR) under the moderate emissions, however, is observed in beginning of the mid-century ranging from $229.4 \%$ to $330.9 \%$. The medians change barely through the entire simulation period. Spring surface runoff, under RCP6.0, has overall length of IQR shorter than the that of RCP4.5 indicating less variations in percent changes except for beginning (40s) and end (80s) of the simulation period. The largest IQR under the severe scenario is estimated for the end of the late-century period (90s) with variations ranging from $278.8 \%$ to $731.2 \%$. The smallest IQR, however, is estimated during the end of the mid-century (60s) ranging from $272.4 \%$ to $517.3 \%$. Medians, under the RCP6.0, follow the general pattern of increasing towards the end of the century. Figure 13 indicates the expected difference between moderate and severe emissions. Comparison of Spring surface runoff under both scenarios shows significant differences during the beginning of the simulation where moderate emissions make shortest IQR while severe emissions make one the largest variations. Figure 13 indicates more outliers are projected under moderate emissions. The variations for Summer surface runoff can be as large as Spring's.

Through the entire simulation period the overall IQR for Summer surface runoff under RCP6.0 is larger than that of Rcp4.5 indicating more variations under severe emissions. Under RCP4.5 medians increase towards the end the century with the highest of $465 \%$ during 80 s and the lowest of $221 \%$ during the 50 s. under RCP4.5, the largest IQR is projected for the middle of the mid-century (50s) period and the shortest IQR for Summer surface runoff is estimated for the beginning pf the late-century period (70s). Summer surface runoff under sever emissions has higher variations. The largest IQR, under RCP6.0, is estimated during the end of the late-century period ranging from $207.6 \%$ to $615.6 \%$ and the shortest IQR ranging is projected during 50 s ranging from $146.7 \%$ to $342 \%$. For Fall surface runoff variation, under both emission scenarios, the medians follow the increasing pattern towards the end of the century (slight increase under RCP4.5 and more accelerated increase under RCP6.0). Under severe emissions, however, more outliers are observed indicating more extremes. The overall length for IQR varies through the simulation for both scenarios. The percent change values for Fall are also as high as Spring's and Summer's indicating several fold surface runoffs during Fall too. Under RCP4.5 the largest IQR is projected at the beginning of the late-century period (70s) ranging from $138 \%$ to $510 \%$. The shortest IQR, however, is observed for a decade after that during 80 s. Under RCP6.0, the largest and shortest IQR ranging from $44.7 \%$ to $434.4 \%$ and from $239.9 \%$ to $387 \%$ is estimated during the beginning (40s) and the end (60s) of the mid-century period, respectively. For Winter surface runoff the overall length of IQR under moderate emissions is greater than that of sever emissions indicating more variation compared to the baseline period. Under both scenarios, medians follow slight increase pattern towards the end of the simulation period. Under RCP4.5, the largest IQR ranging from $133 \%$ to $605.1 \%$ is projected at the middle of the late-century period (80s) and the shortest IQR (smallest variations) is estimated for 50s. Under RCP6.0, however, the largest variations (IQR) ranging from 103\% to $349 \%$ is expected during the beginning of the mid-century period, and the shortest IQR is observed during the middle of the late-century period. Water yield percent change variations from figure 13 indicates both increasing and decreasing amounts through all seasons.

Under moderate emissions, medians appear to follow slight decreasing pattern towards the end of the century and under sever emissions the pattern turns into slight increasing trend by end of the simulation period. Since the surface runoff and water yield are related, water yield follows the same pattern as the surface runoff does (Arnold, Kiniry et al. 2013). For Spring water yield, under RCP4.5, the largest IQR ranging from $-38.2 \%$ to $68.6 \%$ is projected to happen during the middle of the mid-century period and the shortest IQR ranging from $-14 \%$ to $9.7 \%$ is observed during the start of the mid-century indicating the smallest changes of water yield amount compared to the baseline period. While the beginning of the simulation period has the smallest variations of water yield under RCP4.5, severe emission projects largest IQR ranging $-50.2 \%$ to $32.9 \%$. Under RCP6.0, the shortest IQR ranging from $-0.5 \%$ to $37.2 \%$ is observed during 70 s. For Summer water yield, variations under RCP6.0 appears to be greater. This discrepancy is more obvious in the beginning and at the end of the simulation period. Under RCP4.5, the largest IQR ranging from $-28.7 \%$ to $38.8 \%$ is projected at the beginning of the late-century period (70s). The shortest IQR (from - $15 \%$ to $7.2 \%$ ), 
however, is expected at the beginning of the mid-century period (40s). RCP4.5 has resulted in more outliers than RCP6.0 indicating higher chance of extreme amounts. Summer water yield, under sever emissions, shows longer IQR and less outlier. The largest IQR is observed during the middle of the simulation period (60s and $70 \mathrm{~s}$ ) ranging from $-23 \%$ to $62 \%$. The smallest variations ( $-16.5 \%$ to $24.7 \%)$, however, is estimated during the middle of the late century. For Fall water yield variations, medians under both scenarios show mild changes towards the end the century. The overall length of IQR under RCP6.0 is longer than that of RCP4.5, indicating more variations under severe emissions. The largest IQR under RCP4.5 is estimated during 50 s (ranging from $-24.6 \%$ to $63 \%$ ). The shortest IQR, however, is observed during 80 s with ranging from $-21.9 \%$ to $14.21 \%$. Under severe emissions, the largest variations are projected during $50 \mathrm{~s}$ (middle of the mid-century period) ranging from $-62.2 \%$ to $30.4 \%$. The shortest IQR is estimated in the beginning of the simulation period (40s) with ranges of $-10.2 \%$ and $32.9 \%$. Winter water yield projections indicate decrease during the mid-century period and slight increase by end of the century under both emission scenarios. Under RCP4.5 medians increase slightly by end of the century. Under RCP6.0, however, the trend shows no change. Under RCP4.5, the largest and the shortest IQR ranging from $+41.8 \%$ to $23.6 \%$ and from $-18.8 \%$ to $4.3 \%$ are estimated during $80 \mathrm{~s}$ and 90 s, respectively. During Winter, water yield for late-century period, RCP4.5 projects wide variations while RCP6.0 projects small changes compared to the base line.

ET has the smallest changes and variations compared to other hydrologic variables during all seasons. Positive changes of ET during Spring show general increase. Through the mid-century period ET decreases (RCP4.5) while during the late-century it increases towards the end of the period. Under RCP6.0 during the late-century decreases are observed while RCP4.5 shows ET increase during the period. Under RCP4.5, the largest and shortest IQR ranging from $-0.7 \%$ to $8.5 \%$ and from $-1.5 \%$ to $3.3 \%$ are estimated during $90 \mathrm{~s}$ and $80 \mathrm{~s}$, respectively. Under RCP6.0, however, the largest (ranging from $-3.8 \%$ to $6.7 \%$ ) and the shortest (ranging from $0.9 \%$ to $4.7 \%$ ) IQR are observed in the beginning of the simulation period (40s and $50 \mathrm{~s}$ ). During Summer, ET is expected to decrease always under RCP6.0. Since the medians also decrease towards the end the century, it indicates accelerated decrease with approaching to the end the simulation period. Under RCP4.5, however, Et increases sometimes. Under RCp4.5 medians follow slight decreasing pattern. The largest (ranging from $-4.6 \%$ to $3.9 \%$ ) and the shortest (ranging from $-1.99 \%$ to $-0.02 \%$ ) IQR is projected during middle of the late century (80s) and middle of the mid-century (50s) respectively. Under RCP6.0 the largest (ranging from $-9.2 \%$ to $0.5 \%$ ) variation is expected during $60 \mathrm{~s}$ and smallest (ranging from (ranging from $-4.9 \%$ to $-1.6 \%$ ) variation of ET compared to baseline is estimated at the beginning of the simulation (40s). ET during Fall shows decrease for both scenarios and for the entire period. The projections indicate that the largest decrease is estimated during Fall and under RCP6.0 up to -23.5\% during 50s. During Fall, the overall length of IQR under RCP6.0 is longer than that of RCP4.5 indicating more extreme variations under severe emissions. Under RCP6.0 the largest (ranging from $-22.3 \%$ to $-3.7 \%$ ) and the shortest (ranging from $-19.1 \%$ to $11 \%$ ) IQR is estimated during 60 s and 70 s, respectively. Projection for ET during Winter follows the same pattern as Summer. Under moderate emissions the medians during the mid- and latecentury increases. The overall length of IQR under RCP4.5 is greater than that of RCP6.0 meaning more variation under moderate emissions. Under sever emission decreases are estimated during the late-century while moderate emission projections show lesser decrease or increase. Under RCP6.0 the largest (ranging from $-2.1 \%$ to $11.3 \%$ ) and the shortest (ranging from $-0.9 \%$ to $1.3 \%$ ) IQR are observed during mid-century in the middle $(50 \mathrm{~s})$ and the end $(60 \mathrm{~s})$ of the period, respectively.

\section{Implication of future water regime:}

Here we integrated two types of projection: land use and climate data. Therefore, changes regarding land use and climate are the two main factors that affected the water regime (Wang, Kalin et al. 2014). Results show consistency between the moderate and the severe emission scenarios regarding the projected hydrological variables. Through the simulation period precipitation increases, consequently, annual discharge increases. This increase is intensified by growing urbanization. Land use classes of URMD, URHD, and UIDU change from the mid-century period to the late-century period by $10 \%, 47 \%$, and $12.5 \%$, respectively. Therefore, even decreases of precipitation or attenuation in increase of rainfall towards the end of the century, is compensated by more increasing impermeable land covers. These land use changes are along with $23.1 \%$ decrease in 
forest cover (FRSE, FRSD, FRST), 14.7\% hay cover (HAY) and $11.8 \%$ agricultural cover (AGRR). RCP4.5 stabilizes atmospheric radiative forcing at $4.5 \mathrm{~W} / \mathrm{m}^{2}\left(650 \mathrm{ppm} \mathrm{CO}_{2}\right.$ eq) in 2100 (Thomson, Calvin et al. 2011; Van Vuuren, Edmonds et al. 2011), however, by end of the mid-century period, the increase in the radiative forcing attenuates significantly. Unlike, RCP4.5, RCP6.0 keep increasing by end of the century and stabilizes the radiative forcing at $6.0 \mathrm{~W} / \mathrm{m}^{2}$ (850 ppm CO2 eq), however, GHG emissions declines after the end of the mid-century period (Van Vuuren, Edmonds et al. 2011). Therefore, under RCP6.0 precipitation increase during the mid-century and it declines during the late-century period. As a result, this decline is expected to reflect in discharge amount, but urban-oriented land use change results in increased discharge. Similarly, surface runoff and water yield increase in a same manner. However, since discharge and water yield have linked to groundwater (Neitsch, Arnold et al. 2011; Arnold, Kiniry et al. 2013), unlike surface runoff they are indirectly affected. Surface runoff projection increases are significantly greater for all types of monthly, seasonal, and annual values. Annual results, for instance, show at least 3 times higher compared to the baseline. Similar studies have concluded the same result in the region (Wang, Kalin et al. 2014; Sunde, He et al. 2017). Increase in impermeable land covers (URMD, URHD, UIDU) decreases the amount of infiltration into the soil, and subsequently while baseflow contribution declines, surface runoff dramatically increases; this leads to more frequent and intense flooding (Rose and Peters 2001; Huang, Cheng et al. 2008; Wang, Kalin et al. 2014). Combined effects of increasing in precipitation, and temperature as well as imperviousness leads in slight decrease in ET during mid and late century period. Chen et al. (2017) have reported the same result. This indicates increased urbanization compensates increased demand of evaporation and transpiration. Since, the vegetation and tree cover decrease under the land use scenarios, much less transpiration and plant uptake are estimated. It can be concluded that the increase in evaporation due to increase in urbanization cannot be offset by decrease in transpiration. Also decline in soil water consumption and plant uptake due to less vegetation-covered lands can lead to increase in stream flow (Price 2011; Sunde, He et al. 2017). Seasonal percent change analysis (figure 10) indicates that most dramatic changes (more frequent extreme situations) to climate and hydrological variables is projected in the beginning of mid-century period when switching from the moderate to severe emissions. Seasonal behavior also agrees with annual changes; however, it indicates more changes in Winter and Summer. similar results were reported by Sunde et al. 2017 and wang et al. 2013. In a study (Georgakakos, Fleming et al. 2014) for the entire southeast region, decline in storm water has been projected. The general increase in this study can be attributed to urban-oriented land use change as well as the watershed specific characteristics like seasonality and storm frequencies (Villarini and Smith 2010; Sunde, He et al. 2017; Hoyos, Correa-Metrio et al. 2019). Models also had challenges predicting the monthly average temperature, monthly average of maximum temperature, and monthly average of minimum temperature for months of Dec., Jan. and in some cases February.

Previous studies in the region have used CMIP3 or CMIP5 with general bias correction. CMIP5 with finer resolution and LOCA with more reliable climate data, now, have improved the future climate data projections (Pierce, Cayan et al. 2014; Ficklin, Letsinger et al. 2016). More realistic regional patterns of precipitation, better estimates of extreme events, and reduced number of light-precipitation days are the advantages of LOCA (Pierce, Cayan et al. 2014). These improvements have reflected more reliable results in this study. This study helped to fill the a current need to investigate the combined effects of the most recent downscaled and bias-corrected climate projections and the land use projections based on SSP (Shared Socioeconomic Pathways) of Intergovernmental Panel for Climate Change (IPCC). There have been very few studies of this type investigating the integrated effect of projected land use and climate data on hydrological responses southeast US in this study's scale. UCS is mainly forested and agriculture which complicates the impacts and responses. More studies are required to investigate the combined effect of this type of watersheds where notable level of humidity and proximity to the Golf area which is exposed to more hurricanes and tropical storms effects the land use and hydrologic cycle. Wang et al. 2013 have studied an area close to UCS under CMIP3 and concluded the same results of this study. Because of the few number of research in the region where UCS locates and the also because of the approach used in this research, the result and projections brought here can be put in the overall research body and also can be served as a basis for comparison and decision making process. The approach also can be utilized for other watersheds to investigate the integrate 
the land use and climate projections to study the hydrologic response. A few Native American Reservations are located within UCS; therefore, this study can also be used to research the future climate impact on the reservations' sustainability and the people. However, it should be noticed that we used SWAT weather generator to simulate wind speed, relative humidity, and solar radiation. The soil condition has not been changed i.e. for all models the current condition was used.

\section{Conclusion:}

This study presented a method that integrated future climate and land use projection with a hydrologic model to investigate the water balance under combined effect of climate change and land use change. To address some level of the uncertainty with the approach we used three CMIP5 GCM outputs under two emission scenarios (RCP4.5 and RCP6.0). the future time period was split in two time period (mid-century and late-century). Calibration and sensitivity analyses were carried out to make sure the hydrologic model output is reliable. Results show increase in temperature and precipitation in UCS. Annual maximum and minimum temperature are projected to increase up to $30 \%$ especially during Summer and Winter. Rainfall will also increase by around $11 \%$, however different emission scenarios showed different trend through the simulation period. surface runoff, water yield, and discharge at the two stations were estimated to increase. However, surface runoff changes were the largest. Increases in discharge during Summer and Fall are more extreme than other seasons. ET has the modest changes and is expected to decrease. This study can be helpful as an example for areas that mainly comprised of forest and agricultural cover. Additionally, this study can provide information for investigating how future climate data and land use projections could impact hydrological processes. In Southeastern watersheds. This region has not been under focus for climate and land use management studies. Moreover, data and results shown here can provide help in sustainable management especially for Native American Reservations located within Upper Choctawhatchee subbasin. The model used here, showed satisfactory performance that can be further used to study best management practices, water quality modelling (NPS and PS pollution) and also to track extreme weather footprint such as hurricane and tropical storms, and droughts which have been more frequent recently.

\section{Data Availability Statement:}

"The data that support the findings of this study are openly available in [Bureau of Reclamation] at [https://gdo-dcp.ucllnl.org/], reference number [19]".

\section{Acknowledgment:}

The work was supported by the National Institute of Food and Agriculture of USDA through Grant No. 2018-68002-27920 to Florida A\&M University.

"We acknowledge the modeling groups, the Program for Climate Model Diagnosis and Intercomparison (PCMDI) and the WCRP's Working Group on Coupled Modelling (WGCM) for their roles in making available the WCRP CMIP3 multi-model dataset. Support of this dataset is provided by the Office of Science, U.S. Department of Energy."

\section{Reference:}

1. (EnvironmentalProtectionAgency), U. S. E. (2017). Updates To The Demographic And Spatial Allocation Models To Produce Integrated Climate And Land Use Scenarios (ICLUS) (Final Report, Version 2), U.S. Environmental Protection Agency, Washington, DC.

2. (GCX), G. C. E. (2020). ICLUS v2.1 land use projections for the Fourth National Climate Assessment (SSP5), U.S. EPA (Environmental Protection Agency).

3. Abbaspour, K. (2015). "SWAT Calibration and Uncertainty Programs-A User Manual." Swiss Federal Institute of Aquatic Science and Technology: Eawag, Switzerland . 
4. Abbaspour, K. C., et al. (2004). "Estimating uncertain flow and transport parameters using a sequential uncertainty fitting procedure." Vadose Zone Journal 3 (4): 1340-1352.

5. Abbaspour, K. C., et al. (2015). "A continental-scale hydrology and water quality model for Europe: Calibration and uncertainty of a high-resolution large-scale SWAT model." Journal of hydrology524 : 733-752.

6. Abbaspour, K. C., et al. (2007). SWAT-CUP calibration and uncertainty programs for SWAT . MODSIM 2007 international congress on modelling and simulation, modelling and simulation society of Australia and New Zealand.

7. Abbaspour, K. C., et al. (2007). "Modelling hydrology and water quality in the pre-alpine/alpine Thur watershed using SWAT." Journal of hydrology 333 (2-4): 413-430.

8. Allen, R. G. (1986). "A Penman for all seasons." Journal of Irrigation and Drainage Engineering 112 (4): $348-368$.

9. Allen, R. G., et al. (1989). "Operational estimates of reference evapotranspiration." Agronomy journal 81 (4): 650-662.

10. Andersson, J. C., et al. (2012). "Improved SWAT Model Performance With Time-Dynamic Voronoi Tessellation of Climatic Input Data in Southern Africa 1." JAWRA Journal of the American Water Resources Association 48 (3): 480-493.

11. Arnell, N. W. and S. N. Gosling (2013). "The impacts of climate change on river flow regimes at the global scale." Journal of hydrology 486 : 351-364.

12. Arnold, J., et al. (2011). "Soil and Water Assessment Tool input/output file documentation: Version 2009." Texas Water Resources Institute Technical Report 365.

13. Arnold, J., et al. (2013). SWAT 2012 input/output documentation, Texas Water Resources Institute.

14. Arnold, J. G. and N. Fohrer (2005). "SWAT2000: current capabilities and research opportunities in applied watershed modelling." Hydrological Processes: An International Journal19 (3): 563-572.

15. Arnold, J. G., et al. (2012). "SWAT: Model use, calibration, and validation." Transactions of the $A S A B E \mathbf{5 5}$ (4): 1491-1508.

16. Arnold, J. G., et al. (1998). "Large area hydrologic modeling and assessment part I: model development 1." JAWRA Journal of the American Water Resources Association 34 (1): 73-89.

17. ASABE, A. S. o. A. a. B. E. (Jun. 2017). Guidelines for Calibrating, Validating, and Evaluating Hydrologic and Water Quality (H/WQ) Models. 2950 Niles Road, St. Joseph, MI, US.

18. Bierwagen, B. G., et al. (2010). "National housing and impervious surface scenarios for integrated climate impact assessments." Proceedings of the National Academy of Sciences107 (49): 20887-20892.

19. Bureau of Reclamation, C. A. G., Climate Central, Lawrence Livermore National Laboratory, Santa Clara University, Scripps Institution of Oceanography, U.S. Army Corps of Engineers, U.S. Geological Survey (2013). Downscaled CMIP3 and CMIP5 Climate and Hydrology Projections.

20. Carter, L. M., et al. (2014). Southeast and the Caribbean. Climate change impacts in the United States: The third national climate assessment : 396-417.

21. Cecílio, R. A., et al. (2019). "Modeling the influence of forest cover on streamflows by different approaches." Catena 178 : 49-58.

22. Chanapathi, T., et al. (2018). "Analysis of rainfall extremes and water yield of Krishna river basin under future climate scenarios." Journal of Hydrology: Regional Studies 19 : 287-306.

23. Chen, J., et al. (2011). "Overall uncertainty study of the hydrological impacts of climate change for a Canadian watershed." Water Resources Research 47 (12).

24. Chen, Y., et al. (2017). "Modeling the effects of land use change from cotton (Gossypium hirsutum L.) to perennial bioenergy grasses on watershed hydrology and water quality under changing climate." Agricultural Water Management 192 : 198-208.

25. Chen, Y., et al. (2019). "Simulating the impacts of climate change on hydrology and crop production in the Northern High Plains of Texas using an improved SWAT model." Agricultural Water Management 221 : 13-24.

26. Cho, J., et al. (2009). "Effect of spatial distribution of rainfall on temporal and spatial uncertainty of SWAT output." Transactions of the ASABE 52 (5): 1545-1556. 
27. Christensen, J. H. and O. B. Christensen (2007). "A summary of the PRUDENCE model projections of changes in European climate by the end of this century." Climatic change 81 (1): 7-30.

28. Cisneros, J., et al. (2014). Freshwater resources.

29. Clarke, L., et al. (2007). "Scenarios of greenhouse gas emissions and atmospheric concentrations."

30. Diffenbaugh, N. S., et al. (2013). "Robust increases in severe thunderstorm environments in response to greenhouse forcing." Proceedings of the National Academy of Sciences 110 (41): 16361-16366.

31. Diffenbaugh, N. S., et al. (2015). "Anthropogenic warming has increased drought risk in California." Proceedings of the National Academy of Sciences 112 (13): 3931-3936.

32. Dile, Y. T. and R. Srinivasan (2014). "Evaluation of CFSR climate data for hydrologic prediction in data-scarce watersheds: an application in the Blue Nile River Basin." JAWRA Journal of the American Water Resources Association 50 (5): 1226-1241.

33. Donner, L. J., et al. (2011). "The dynamical core, physical parameterizations, and basic simulation characteristics of the atmospheric component AM3 of the GFDL global coupled model CM3." Journal of climate 24 (13): 3484-3519.

34. Emanuel, K. A. (2013). "Downscaling CMIP5 climate models shows increased tropical cyclone activity over the 21st century." Proceedings of the National Academy of Sciences110 (30): 12219-12224.

35. Ficklin, D. L. and B. L. Barnhart (2014). "SWAT hydrologic model parameter uncertainty and its implications for hydroclimatic projections in snowmelt-dependent watersheds." Journal of hydrology 519 : 2081-2090.

36. Ficklin, D. L., et al. (2016). "Assessing differences in snowmelt-dependent hydrologic projections using CMIP3 and CMIP5 climate forcing data for the western United States." Hydrology Research 47 (2): 483-500.

37. Field, C. B., et al. (2012). Managing the risks of extreme events and disasters to advance climate change adaptation: special report of the intergovernmental panel on climate change, Cambridge University Press.

38. Flato, G., et al. (2014). Evaluation of climate models. Climate change 2013: the physical science basis. Contribution of Working Group I to the Fifth Assessment Report of the Intergovernmental Panel on Climate Change, Cambridge University Press: 741-866.

39. Fowler, H. J., et al. (2007). "Linking climate change modelling to impacts studies: recent advances in downscaling techniques for hydrological modelling." International Journal of Climatology: A Journal of the Royal Meteorological Society 27 (12): 1547-1578.

40. Fu, G., et al. (2013). "Modelling runoff with statistically downscaled daily site, gridded and catchment rainfall series." Journal of hydrology 492 : 254-265.

41. Fujino, J., et al. (2006). "Multi-gas mitigation analysis on stabilization scenarios using AIM global model." The Energy Journal (Special Issue\# 3).

42. Fuka, D. R., et al. (2014). "Using the Climate Forecast System Reanalysis as weather input data for watershed models." Hydrological processes 28 (22): 5613-5623.

43. Galvan, L., et al. (2014). "Rainfall estimation in SWAT: An alternative method to simulate orographic precipitation." Journal of hydrology 509 : 257-265.

44. Gao, Y., et al. (2015). "Persistent cold air outbreaks over North America in a warming climate." Environmental Research Letters10 (4): 044001.

45. Gassman, P. W., et al. (2007). "The soil and water assessment tool: historical development, applications, and future research directions." Transactions of the ASABE 50 (4): 1211-1250.

46. Gent, P. R., et al. (2011). "The community climate system model version 4." Journal of climate 24 (19): 4973-4991.

47. Georgakakos, A., et al. (2014). Chapter 3: Water resources. Climate Change Impacts in the United States: The Third National Climate Assessment U.S. Global Change Research Program: 69-112.

48. Ghoraba, S. M. (2015). "Hydrological modeling of the Simly Dam watershed (Pakistan) using GIS and SWAT model." Alexandria Engineering Journal 54 (3): 583-594.

49. Green, C. and A. Van Griensven (2008). "Autocalibration in hydrologic modeling: Using SWAT2005 in small-scale watersheds." Environmental Modelling \&3 Software 23 (4): 422-434. 
50. Groisman, P. Y., et al. (2005). "Trends in intense precipitation in the climate record." Journal of climate 18 (9): 1326-1350.

51. Gupta, H. V., et al. (1999). "Status of automatic calibration for hydrologic models: Comparison with multilevel expert calibration." Journal of Hydrologic Engineering 4 (2): 135-143.

52. Hidalgo Leon, H. G., et al. (2008). "Downscaling with constructed analogues: Daily precipitation and temperature fields over the United States."

53. Hinson, A. S., et al. (2015). Choctawhatchee, Pea and Yellow Rivers Comprehensive Watershed Management Plan, Geological Survey of Alabama Tuscaloosa, Alabama, US.

54. Hoyos, N., et al. (2019). "Modeling Streamflow Response to Persistent Drought in a Coastal Tropical Mountainous Watershed, Sierra Nevada De Santa Marta, Colombia." Water 11 (1): 94.

55. Huang, H. j., et al. (2008). "Effect of growing watershed imperviousness on hydrograph parameters and peak discharge." Hydrological Processes: An International Journal22 (13): 2075-2085.

56. Ingram, K. T., et al. (2013). Forests and climate change in the Southeast USA. Climate of the Southeast United States, Springer: 165-189.

57. Joh, H.-K., et al. (2011). "Assessing climate change impact on hydrological components of a small forest watershed through SWAT calibration of evapotranspiration and soil moisture." Transactions of the ASABE $\mathbf{5 4}$ (5): 1773-1781.

58. Katz, R. W., et al. (2003). Stochastic modeling of the effects of large-scale circulation on daily weather in the southeastern US.Issues in the Impacts of Climate Variability and Change on Agriculture , Springer: 189-216.

59. Khalid, K., et al. (2016). "Sensitivity analysis in watershed model using SUFI-2 algorithm." Procedia Eng 162 : 441-447.

60. Kundzewicz, Z. W., et al. (2007). "Freshwater resources and their management."

61. Legates, D. R. and G. J. McCabe Jr (1999). "Evaluating the use of "goodness-of-fit" measures in hydrologic and hydroclimatic model validation." Water Resources Research 35 (1): 233-241.

62. Li, H., et al. (2010). "Bias correction of monthly precipitation and temperature fields from Intergovernmental Panel on Climate Change AR4 models using equidistant quantile matching." Journal of Geophysical Research: Atmospheres 115 (D10).

63. Mahmood, R., et al. (2010). "Impacts of land use/land cover change on climate and future research priorities." Bulletin of the American Meteorological Society 91 (1): 37-46.

64. Manuel, J. (2008). Drought in the southeast: lessons for water management, National Institute of Environmental Health Sciences.

65. Maraun, D., et al. (2010). "Precipitation downscaling under climate change: Recent developments to bridge the gap between dynamical models and the end user." Reviews of Geophysics 48 (3).

66. Masih, I., et al. (2011). "Assessing the Impact of Areal Precipitation Input on Streamflow Simulations Using the SWAT Model 1." JAWRA Journal of the American Water Resources Association 47 (1): 179-195.

67. Masui, T., et al. (2011). "An emission pathway for stabilization at $6 \mathrm{Wm}-2$ radiative forcing." Climatic change 109 (1-2): 59.

68. McNulty, S., et al. (2013). Forests and climate change in the Southeast USA. Climate of the Southeast United States: Variability, change, impacts, and vulnerability . Washington, DC: Island Press, Springer: 165-189.

69. Meehl, G. A., et al. (2012). "Mechanisms contributing to the warming hole and the consequent US east-west differential of heat extremes." Journal of climate 25 (18): 6394-6408.

70. Meehl, G. A., et al. (2007). "Global climate projections."

71. Meinshausen, M., et al. (2011). "The RCP greenhouse gas concentrations and their extensions from 1765 to 2300." Climatic change109 (1-2): 213.

72. Monteith, J. L. (1965). Evaporation and environment. Symposia of the society for experimental biology, Cambridge University Press (CUP) Cambridge.

73. Moriasi, D., et al. (2012). "Hydrologic and water quality models: Use, calibration, and validation." Transactions of the ASABE55 (4): 1241-1247. 
74. Moriasi, D. N., et al. (2007). "Model evaluation guidelines for systematic quantification of accuracy in watershed simulations." Transactions of the ASABE $\mathbf{5 0}$ (3): 885-900.

75. Morris, M. D. (1991). "Factorial sampling plans for preliminary computational experiments." Technometrics 33 (2): 161-174.

76. Moss, R., et al. (2008). Towards New Scenarios for Analysis of Emissions . Climate Change, Impacts, and Response Strategies (IPCC Expert Meeting Report, IPCC, Geneva, 2008).

77. Moss, R. H., et al. (2010). "The next generation of scenarios for climate change research and assessment." Nature 463 (7282): 747-756.

78. MRLC-Consortium, M.-R. L. C. (2019). Retrieved 11 Dec. 2019, from https://www.mrlc.gov/data.

79. Nakicenovic, N., et al. (2000). Special report on emissions scenarios (SRES), a special report of Working Group III of the intergovernmental panel on climate change, Cambridge University Press.

80. Nash, J. E. and J. V. Sutcliffe (1970). "River flow forecasting through conceptual models part I-A discussion of principles." Journal of hydrology 10 (3): 282-290.

81. Neitsch, S. L., et al. (2011). Soil and water assessment tool theoretical documentation version 2009, Texas Water Resources Institute.

82. NRC, N. R. C. and C. R. C. CRC (2005). Radiative Forcing of Climate Change: Expanding the Concept and Addressing Uncertainties, National Academies Press.

83. O'Neil, P., et al. (2006). "Habitat and biological assessment of the Terrapin Creek watershed and development of the index of biotic integrity for the Coosa and Tallapoosa River systems." Open-File Report 601 .

84. Osei, M. A., et al. (2019). "The impact of climate and land-use changes on the hydrological processes of Owabi catchment from SWAT analysis." Journal of Hydrology: Regional Studies 25 : 100620.

85. Ouyang, F., et al. (2015). "Impacts of climate change under CMIP5 RCP scenarios on streamflow in the Huangnizhuang catchment." Stochastic environmental research and risk assessment29 (7): 17811795.

86. Pachauri, R. K., et al. (2014). Climate change 2014: synthesis report. Contribution of Working Groups I, II and III to the fifth assessment report of the Intergovernmental Panel on Climate Change, Ipcc.

87. Pandey, B. K., et al. (2019). "Climate change impact assessment on blue and green water by coupling of representative CMIP5 climate models with physical based hydrological model." Water resources management 33 (1): 141-158.

88. Pierce, D. and D. Cayan (2016). "Downscaling humidity with localized constructed analogs (LOCA) over the conterminous united states." Climate dynamics 47 (1-2): 411-431.

89. Pierce, D. W., et al. (2015). "Improved bias correction techniques for hydrological simulations of climate change." Journal of Hydrometeorology 16 (6): 2421-2442.

90. Pierce, D. W., et al. (2014). "Statistical downscaling using localized constructed analogs (LOCA)." Journal of Hydrometeorology 15 (6): 2558-2585.

91. Poloczanska, E., et al. (2018). The IPCC Special Report on the Ocean and Cryosphere in a Changing Climate . 2018 Ocean Sciences Meeting, AGU.

92. Price, K. (2011). "Effects of watershed topography, soils, land use, and climate on baseflow hydrology in humid regions: A review." Progress in physical geography 35 (4): 465-492.

93. Qiu, J., et al. (2019). "Quantifying effects of conservation practices on non-point source pollution in the Miyun Reservoir Watershed, China." Environmental monitoring and assessment191 (9): 582.

94. Riahi, K., et al. (2007). "Scenarios of long-term socio-economic and environmental development under climate stabilization." Technological Forecasting and Social Change 74 (7): 887-935.

95. Riahi, K., et al. (2011). "RCP 8.5-A scenario of comparatively high greenhouse gas emissions." Climatic change 109 (1-2): 33.

96. Riahi, K., et al. (2017). "The shared socioeconomic pathways and their energy, land use, and greenhouse gas emissions implications: an overview." Global Environmental Change 42 : 153-168.

97. Ritchie, J. T. (1972). "Model for predicting evaporation from a row crop with incomplete cover." Water Resources Research8 (5): 1204-1213.

98. Rose, S. and N. E. Peters (2001). "Effects of urbanization on streamflow in the Atlanta area (Georgia, 
USA): a comparative hydrological approach." Hydrological processes 15 (8): 1441-1457.

99. Roth, V. and T. Lemann (2016). "Comparing CFSR and conventional weather data for discharge and soil loss modelling with SWAT in small catchments in the Ethiopian Highlands." Hydrology and Earth System Sciences 20 (2): 921-934.

100. Saha, S., et al. (2010). "The NCEP climate forecast system reanalysis." Bulletin of the American Meteorological Society 91 (8): 1015-1058.

101. Saltelli, A., et al. (2004). Sensitivity analysis in practice: a guide to assessing scientific models, Wiley Online Library.

102. Sanderson, B. M., et al. (2015). "Addressing interdependency in a multimodel ensemble by interpolation of model properties." Journal of climate 28 (13): 5150-5170.

103. Sanderson, B. M., et al. (2015). "A representative democracy to reduce interdependency in a multimodel ensemble." Journal of climate 28 (13): 5171-5194.

104. Santhi, C., et al. (2001). "Validation of the swat model on a large river basin with point and nonpoint sources 1." JAWRA Journal of the American Water Resources Association 37 (5): 1169-1188.

105. Schmidt, G. A., et al. (2006). "Present-day atmospheric simulations using GISS ModelE: Comparison to in situ, satellite, and reanalysis data." Journal of climate 19 (2): 153-192.

106. Seaber, P. R., et al. (1987). "Hydrologic unit maps."

107. Sleeter, B. M., et al. (2018). Land Cover and Land-Use Change.Impacts, Risks, and Adaptation in the United States: Fourth National Climate Assessment . D. R. Reidmiller, C. W. Avery, D. R. Easterling et al. U.S. Global Change Research Program, Washington, DC, USA. Volume II: 202-231.

108. Smith, S. J. and T. Wigley (2006). "Multi-gas forcing stabilization with Minicam." The Energy Journal (Special Issue\# 3).

109. Sobel, A. H., et al. (2016). "Human influence on tropical cyclone intensity." Science 353 (6296): $242-246$.

110. Sohl, T. L., et al. (2014). "Spatially explicit modeling of 1992-2100 land cover and forest stand age for the conterminous United States." Ecological Applications 24 (5): 1015-1036.

111. Sohl, T. L., et al. (2016). "Divergent projections of future land use in the United States arising from different models and scenarios." Ecological Modelling 337 : 281-297.

112. SoilSurvey (2019). "National Value Added Look Up (value) Table Database for the Gridded Soil Survey Geographic (gSSURGO) Database for the United States of America and the Territories, Commonwealths, and Island Nations served by the USDA-NRCS." Retrieved 10 July 2019 2019, from https://gdg.sc.egov.usda.gov/.

113. SoilSurvey (2019). "Natural Resources Conservation Service, United States Department of Agriculture." Retrieved 21 Sep. 2019, 2019, from http://websoilsurvey.nrcs.usda.gov/.

114. Sudheer, K., et al. (2011). "Application of a pseudo simulator to evaluate the sensitivity of parameters in complex watershed models." Environmental Modelling 83 Software 26 (2): 135-143.

115. Sun, G. (2013). Impacts of climate change and variability on water resources in the Southeast USA. Climate of the Southeast United States, Springer: 210-236.

116. Sunde, M. G., et al. (2017). "Integrating downscaled CMIP5 data with a physically based hydrologic model to estimate potential climate change impacts on streamflow processes in a mixed-use watershed." Hydrological processes 31 (9): 1790-1803.

117. Taylor, K. E., et al. (2011). CMIP5 data reference syntax (DRS) and controlled vocabularies . PCMDI.

118. Taylor, K. E., et al. (2012). "An overview of CMIP5 and the experiment design." Bulletin of the American Meteorological Society 93 (4): 485-498.

119. Teutschbein, C. and J. Seibert (2010). "Regional climate models for hydrological impact studies at the catchment scale: a review of recent modeling strategies." Geography Compass 4 (7): 834-860.

120. Thomson, A. M., et al. (2011). "RCP4. 5: a pathway for stabilization of radiative forcing by 2100." Climatic change109 (1-2): 77.

121. Trail, M., et al. (2013). "Potential impact of land use change on future regional climate in the Southeastern US: reforestation and crop land conversion." Journal of Geophysical Research: Atmospheres $\mathbf{1 1 8}$ (20): $11,577-511,588$. 
122. Tuo, Y., et al. (2016). "Evaluation of precipitation input for SWAT modeling in Alpine catchment: A case study in the Adige river basin (Italy)." Science of the total environment 573 : 66-82.

123. U.S.GeologicalSurvey (2017). "1/3rd arc-second Digital Elevation Models (DEMs) - USGS National Map 3DEP Downloadable Data Collection: U.S. Geological Survey."

124. USWeatherService (2019). " "U.S. Climate Data." Retrieved 11 Dec. 2019, 2019, from www.usclimatedata.com/.

125. Van Vuuren, D. P., et al. (2007). "Stabilizing greenhouse gas concentrations at low levels: an assessment of reduction strategies and costs." Climatic change 81 (2): 119-159.

126. Van Vuuren, D. P., et al. (2011). "The representative concentration pathways: an overview." Climatic change 109 (1-2): 5.

127. Van Vuuren, D. P., et al. (2011). "RCP2. 6: exploring the possibility to keep global mean temperature increase below 2 C." Climatic change 109 (1-2): 95.

128. Veettil, A. V. and A. K. Mishra (2016). "Water security assessment using blue and green water footprint concepts." Journal of hydrology 542: 589-602.

129. Villarini, G., et al. (2009). "On the stationarity of annual flood peaks in the continental United States during the 20th century." Water Resources Research 45 (8).

130. Villarini, G. and J. A. Smith (2010). "Flood peak distributions for the eastern United States." Water Resources Research46 (6).

131. Vose, R., et al. (2017). Temperature changes in the United States.Climate Science Special Report: Fourth National Climate Assessment. D. J. Wuebbles, D. W. Fahey, K. A. Hibbard et al., U.S. Global Change Research Program, Washington, DC, USA. Volume I: 185-206.

132. Walsh, J., et al. (2014). Ch. 2: Our Changing Climate. Climate Change Impacts in the United States: The Third National Climate Assessment, JM Melillo, Terese (TC) Richmond, and GW Yohe, Eds., US Global Change Research Program, 19-67. doi: 10.7930/J0KW5CXT.

133. Wang, R., et al. (2014). "Individual and combined effects of land use/cover and climate change on Wolf Bay watershed streamflow in southern Alabama." Hydrological processes 28 (22): 5530-5546.

134. Wear, D. N. (2011). "Forecasts of county-level land uses under three future scenarios: a technical document supporting the Forest Service 2010 RPA Assessment." Gen. Tech. Rep. SRS-141. Asheville, NC: US Department of Agriculture Forest Service, Southern Research Station. 41 p. 141 : 1-41.

135. Wilby, R. L., et al. (2000). "Hydrological responses to dynamically and statistically downscaled climate model output." Geophysical Research Letters 27 (8): 1199-1202.

136. Williams, J. R. (1969). "Flood routing with variable travel time or variable storage coefficients." Transactions of the ASAE12 (1): 100-0103.

137. Winchell, M., et al. (2013). "ArcSWAT Interface for SWAT2012. User's Guide. 464 pp." Temple, TX: Blackland Research and Extension Center,Texas AgriLife Research, College Station .

138. Wise, M., et al. (2009). "Implications of limiting CO2 concentrations for land use and energy." Science 324 (5931): 1183-1186.

139. Yang, L., et al. (2018). "A new generation of the United States National Land Cover Database: Requirements, research priorities, design, and implementation strategies." ISPRS journal of photogrammetry and remote sensing 146 : 108-123.

\section{Hosted file}

Figures . docx available at https://authorea.com/users/334986/articles/460928-evaluating-waterbalance-variables-under-land-use-and-climate-projections-in-heavily-forested-watershedin-a-humid-region

\section{Hosted file}

Tables.docx available at https://authorea.com/users/334986/articles/460928-evaluating-waterbalance-variables-under-land-use-and-climate-projections-in-heavily-forested-watershedin-a-humid-region 